\title{
Aerosol concentration and size distribution measured below, in, and above cloud from the DOE G-1 during VOCALS-REx
}

\author{
L. I. Kleinman ${ }^{1}$, P. H. Daum ${ }^{1}$, Y.-N. Lee ${ }^{1}$, E. R. Lewis ${ }^{1}$, A. J. Sedlacek III $^{1}$, G. I. Senum ${ }^{1}$, S. R. Springston ${ }^{1}$, J. Wang ${ }^{1}$, \\ J. Hubbe ${ }^{2}$, J. Jayne ${ }^{3}$, Q. Min ${ }^{4}$, S. S. Yum ${ }^{5}$, and G. Allen ${ }^{6}$ \\ ${ }^{1}$ Atmospheric Sciences Division, Brookhaven National Laboratory, Upton, New York, USA \\ ${ }^{2}$ Atmospheric Sciences \& Global Change Division, Pacific Northwest National Laboratory, Richland, Washington, USA \\ ${ }^{3}$ Aerodyne Research Inc., Billerica, Massachusetts, USA \\ ${ }^{4}$ Atmospheric Sciences Research Center, State University of New York, Albany, New York, USA \\ ${ }^{5}$ Department of Atmospheric Sciences, Yonsei University, Seoul 120749, South Korea \\ ${ }^{6}$ Centre for atmospheric Science, University of Manchester, Manchester M13 9PL, UK
}

Correspondence to: L. I. Kleinman (kleinman@bnl.gov)

Received: 19 May 2011 - Published in Atmos. Chem. Phys. Discuss.: 21 June 2011

Revised: 30 November 2011 - Accepted: 12 December 2011 - Published: 4 January 2012

\begin{abstract}
During the VOCALS Regional Experiment, the DOE G-1 aircraft was used to sample a varying aerosol environment pertinent to properties of stratocumulus clouds over a longitude band extending $800 \mathrm{~km}$ west from the Chilean coast at Arica. Trace gas and aerosol measurements are presented as a function of longitude, altitude, and dew point in this study. Spatial distributions are consistent with an upper atmospheric source for $\mathrm{O}_{3}$ and South American coastal sources for marine boundary layer (MBL) CO and aerosol, most of which is acidic sulfate. Pollutant layers in the free troposphere (FT) can be a result of emissions to the north in Peru or long range transport from the west. At a given altitude in the FT (up to $3 \mathrm{~km}$ ), dew point varies by $40^{\circ} \mathrm{C}$ with dry air descending from the upper atmospheric and moist air having a boundary layer (BL) contribution. Ascent of BL air to a cold high altitude results in the condensation and precipitation removal of all but a few percent of BL water along with aerosol that served as $\mathrm{CCN}$. Thus, aerosol volume decreases with dew point in the FT. Aerosol size spectra have a bimodal structure in the MBL and an intermediate diameter unimodal distribution in the FT. Comparing cloud droplet number concentration (CDNC) and pre-cloud aerosol $\left(D_{p}>100 \mathrm{~nm}\right)$ gives a linear relation up to a number concentration of $\sim 150 \mathrm{~cm}^{-3}$, followed by a less than proportional increase in CDNC at higher aerosol number concentration. A number balance between below cloud aerosol and cloud droplets indicates that $\sim 25 \%$ of aerosol with $D_{p}>100 \mathrm{~nm}$ are interstitial (not activated). A direct comparison of precloud and in-cloud aerosol yields a higher estimate. Artifacts
\end{abstract}

in the measurement of interstitial aerosol due to droplet shatter and evaporation are discussed. Within each of 102 constant altitude cloud transects, CDNC and interstitial aerosol were anti-correlated. An examination of one cloud as a case study shows that the interstitial aerosol appears to have a background, upon which is superimposed a high frequency signal that contains the anti-correlation. The anti-correlation is a possible source of information on particle activation or evaporation.

\section{Introduction}

Satellite observations of cloud droplet effective radius indicate a gradient off the shore of Northern Chile. According to MODIS retrievals from the Aqua satellite for the month of October, average cloud droplet radius over the Pacific Ocean increased from 8 to $14 \mu \mathrm{m}$ from the coast to $1000 \mathrm{~km}$ offshore (Wood et al., 2007). This gradient is plausibly attributed to anthropogenic $\mathrm{SO}_{2}$ from point sources in Chile and Peru, subsequently oxidizded to aerosol sulfate.

Anthropogenic perturbations to marine stratocumulus clouds was one motivation for the VAMOS OceanCloud-Climate-Atmosphere-Land Regional Experiment (VOCALS-REx or VOCALS, for short), an overview of which is provided by Wood et al. (2011). The US DOE G-1 aircraft participated in the international collaboration described by Wood et al. Aboard the G-1 were instruments for in-situ measurements of cloud microphysics, aerosol

Published by Copernicus Publications on behalf of the European Geosciences Union. 
concentration, size distribution, and composition, gasses useful as air mass tracers, and navigational and meteorological parameters. The sampling region of the G-1 extended from Arica, Chile, $800 \mathrm{~km}$ west to $78^{\circ} \mathrm{W}$ mainly within a restricted latitude band between Arica at $18.35^{\circ} \mathrm{S}$ and $20^{\circ} \mathrm{S}$.

Allen et al. (2011) have summarized meteorological conditions and the chemical composition of the boundary layer and free troposphere within one degree of $20^{\circ} \mathrm{S}$ between the coast of Chile and $85^{\circ} \mathrm{W}$, relying on aircraft measurements from the United Kingdom BAe 146, NSF C130, and DOE G1 , supplemented by surface observations from the research vessel Ronald H. Brown. Allen et al. (2011) provide multiple comparisons between platforms which, in general, reveals a high degree of consistency. Bretherton et al. (2010), relying principally on the $\mathrm{C} 130$, and BAe146 long range aircraft, provide a comprehensive synthesis of marine boundary layer and free troposphere structure, clouds, and precipitation along the $20^{\circ} \mathrm{S}$ corridor. Further information on the marine boundary layer and aerosol source attribution is given in Rahn and Garreaud (2010) and Chand et al. (2010), respectively. In this study we provide a more complete treatment of aerosol and trace gas measurements from the DOE G-1 with emphasis on the longitudinal and vertical distribution of aerosol concentration and size distribution. Summary information is provided on aerosol composition derived from Aerosol Mass Spectrometer (AMS) and Particle into Liquid Sampler (PILS) measurements, the primary description of which will be contained in an article by Lee et al. (2011).

Data are presented for the entire field campaign, segregated into subsets according to longitude, altitude, dew point temperature $\left(T_{d}\right)$, or whether measurements are below, in, or above cloud. We find that dew point is a better indicator of air mass type and origin than altitude and thus trends of trace gasses or aerosol as a function of dew point often show less scatter than the same trends considered as a function of altitude.

The concentration and size distribution of interstitial aerosol are described. These are particles observed in-cloud that either never grew into cloud droplets (i.e., were not activated) or having been activated return to being aerosol particles after cloud droplet evaporation. Properties of interstitial aerosol depend on many variables such as aerosol size and composition, cloud updraft velocity, and entrainment of dry air. Interstitial aerosols have been observed at mountain top sites (e.g. Hallberg et al., 1994; Martinsson et al., 1999; Henning et al., 2002; Mertes et al., 2005) and from aircraft (e.g. Leaitch, 1986, 1996; Gillani et al., 1995; Wang et al., 2009). Results range from nearly complete activation of the accumulation mode to a low fractional activation leaving larger interstitial aerosol particles than expected from an adiabatic cloud droplet activation model (Hallberg et al., 1994; Mertes et al., 2005). Discrepancies could be due to external mixtures, the type and quantity of organic aerosol constituents, or entrainment.
Table 1. Aerosol and cloud droplet instruments.

\begin{tabular}{lll}
\hline Instrument & Primary function & $D_{p}$ range \\
\hline CPC3025 $^{1}$ & total aerosol & $>3 \mathrm{~nm}$ \\
CPC3010 $^{1}$ & total aerosol & $>10 \mathrm{~nm}$ \\
SMPS $(D M A)^{2}$ & aerosol mobility size spectra & $15-440 \mathrm{~nm}$ \\
PCASP $^{3}$ & cabin & $0.1-3 \mu \mathrm{m}$ \\
PCASP $^{3}$ & pylon & $0.1-3 \mu \mathrm{m}$ \\
CAS $^{2}$ & cloud droplet & $0.6-56 \mu \mathrm{m}$ \\
CIP $^{2}$ & drizzle & $8-940 \mu \mathrm{m}$ \\
AMS $^{4}$ & aerosol composition & $60-600 \mathrm{~nm}$ \\
PILS $^{5}$ & aerosol composition & $<2 \mu \mathrm{m}$ \\
PSAP $^{6}$ & aerosol absorption & $<2 \mu \mathrm{m}$ \\
\hline
\end{tabular}

${ }^{1}$ TSI; ${ }^{2}$ DMT Inc., model 3081 DMA and model 3010 condensation particle counter for SMPS; ${ }^{3}$ PCASP-100X (Particle Measuring Systems, Inc., Boulder, CO) with SPP200 electronics (Droplet measurement Technologies, Boulder, CO). Size range is nominal; ${ }^{4}$ Aerodyne; ${ }^{5}$ Brookhaven National Laboratory; ${ }^{6}$ Radiance Research.

A simplifying feature of the VOCALS observations is that bulk measurements of aerosol composition indicate a relatively uniform composition of easily activated particles. Incloud sampling of aerosol is, however, problematic. Two artifacts are discussed. Cloud droplet shatter is observed to create high concentrations of small particles $(\sim 50 \mathrm{~nm})$, with a size distribution extending into the accumulation mode range. The shatter contribution to total in-cloud aerosol becomes minor at $\sim D_{p}>100-150 \mathrm{~nm}$. Adiabatic heating in the G-1 aerosol inlet has the potential to evaporate cloud droplets creating aerosol. A number-balance based comparison of pre-cloud aerosol with CDNC yields an estimate that $\sim 25 \%$ of pre-cloud aerosol with $D_{p}>100 \mathrm{~nm}$ is interstitial. An estimate of the interstitial aerosol based on in-cloud measurements, and therefore susceptible to artifact, is larger.

A more robust use of the in-cloud aerosol measurements is in examining the anti-correlation between aerosol interstitial concentration and CDNC. One hundred and two cloud transects were defined and an anti-correlation observed in each. One transect was selected as a case study and used to further illustrate aerosol and cloud droplet variability. A time series and high pass filter showed that the anti-correlation was carried in spikes and dips in aerosol concentration and LWC on a time scale of seconds or less, such as would be produced by an evaporating cloud droplet leaving behind an aerosol particle.

\section{Experimental}

Aerosol properties are reported at ambient temperature and pressure. Local daylight savings times equal to UTC -3 are used in this study. Data are archived at http://iop.archive.arm. gov/arm-iop/0special-data/ASP_Campaigns_past/. (Sign in and follow menu to 2008VOCALS.), which uses UTC time. 


\subsection{Instruments}

Aerosol and cloud instruments used in this study are listed in Table 1. The G-1 had its usual navigational and meteorological package for measuring position, winds, temperature, and dew point (chilled mirror hygrometer) http://www.pnl. gov/atmospheric/programs/raf.stm. $\mathrm{CO}$ and $\mathrm{O}_{3}$ were used as air mass tracers. CO was determined by VUV resonance fluorescence (Resonance Ltd., Barrie, ON, Canada). Ozone was measured by a modified UV absorption detector (Model 49-100, Thermo Electron Corporation, Franklin, MA). $\mathrm{SO}_{2}$ measurements from a modified pulsed fluorescence detector (Model 43S, Thermo Electron Corporation, Franklin, MA) were typically below a 200 ppt limit of detection. Further information on gas phase instruments used in VOCALS can be found in Springston et al. (2005) and Kleinman et al. (2007).

A forward facing two-stage diffuser aerosol inlet system supplied ambient air for aerosol instruments located inside the cabin of the G-1 (Brechtel, 2003). Slowing down air from the G-1 speed of $100 \mathrm{~m} \mathrm{~s}^{-1}$ to a few $\mathrm{m} \mathrm{s}^{-1}$ results in $5^{\circ} \mathrm{C}$ adiabatic heating. Droplet evaporation rates were calculated from the coupled heat and mass transfer equations in McGraw and Liu (2006), (R. McGraw, personal communication, 2011). Most droplets evaporate within one second. Less clear is the transit time of a cloud droplet through the inlet and plumbing inside the aircraft before impaction occurs. Our estimate is that these times scales are competitive. If evaporation occurs before impaction, aerosols so generated would mistakenly be classified as interstitial. Smaller cloud droplets may evaporate in the outside-cabin PCASP due to active and passive heating applied over a residence time estimated to be 0.1-0.3 s (Strapp et al., 1992).

\subsubsection{Aerosol composition}

Aerosol composition was measured via an AMS and PILS and acidity determined by $\mathrm{NH}_{4}^{+}$to $\mathrm{SO}_{4}^{2-}$ ratio and conductivity as described by Lee et al. (2011). They found that nonrefractory, sub-micron size aerosol in the marine boundary layer had an average composition between $\left(\mathrm{NH}_{4}\right) \mathrm{HSO}_{4}$ and $\mathrm{H}_{2} \mathrm{SO}_{4}$ with a $10-15 \%$ admixture of organics. Acidic aerosol with this composition contains significant water even at low relative humidity (RH) (Lee et al., 2011). Based on the E-AIM website, http://www.aim.env.uea.ac.uk/aim/aim.php, (Clegg et al., 1998) a solution consisting of 30 molal each $\mathrm{NH}_{4} \mathrm{HSO}_{4}$ and $\mathrm{H}_{2} \mathrm{SO}_{4}$ is calculated to be in equilibrium at the $\sim 15 \%$ RH used for particle size measurements. The density of this solution is $1.56 \mathrm{~g} \mathrm{~cm}^{-3}$ at $298.15 \mathrm{~K}$, insensitive to temperature (Clegg and Wexler, 2011). If an insoluble organic component with density $1.2 \mathrm{~g} \mathrm{~cm}^{-3}$ comprises $10 \%$ of the aerosol mass, then the volume growth factor at $15 \% \mathrm{RH}$ (calculated as the sum of the volumes of the solution and organic component divided by the sums of the volumes of the solutes and the organic component), is equal to 1.29 , and the radial growth factor is 1.09 .

\subsubsection{Aerosol size distributions}

Size distributions of aerosol particles in the Aitken and accumulation mode were quantified with one minute time resolution using an SMPS (scanning mobility particle sizer) consisting of a cylindrical differential mobility analyzer (DMA) and a condensation particle counter. It is assumed that particles are spherical so that mobility and geometric diameters are equal. Data were analyzed using the inversion algorithms described by Collins et al. (2002). A Nafion dryer upwind of the DMA reduced $\mathrm{RH}$ to $14 \%(1 \sigma=2 \%)$. In reporting "dry" size distributions in this article, water of hydration at $14 \% \mathrm{RH}$ is not taken into account. Reported particle diameters are thus approximately $9 \%$ larger than in the dry state. In the case where there are few particles below the $15 \mathrm{~nm}$ lower limit of detection of the SMPS, the total number of particles in the size range $15-440 \mathrm{~nm}$ should be a good approximation for $\mathrm{CN}$. Comparisons between the CPC3010 $\left(D_{p}>10 \mathrm{~nm}\right)$ and the SMPS generally show agreement within $10 \%$ for sampling periods without appreciable concentrations of small particles.

Two Passive Cavity Aerosol Spectrometer (PCASP) units with SPP-200 electronics upgrade were used to measure aerosol with nominal diameter between 0.1 and $3 \mu \mathrm{m}$. One PCASP was mounted on a pylon on the nose of the aircraft and the other located inside the cabin. In the data archive the two PCASPs are identified as units A and B. Midway through the program these units were switched, so that from the start of the program through 28 October, unit A was outside and unit B inside. From 29 October till the end of the VOCALS campaign, unit $\mathrm{B}$ was outside and unit $\mathrm{A}$ inside. The relative humidity of air sampled by both PCASPs was decreased by the use of deicing heaters which yields an increase in temperature, reported to be 10 to $20^{\circ} \mathrm{C}$ (Strapp et al., 1992; Hallar et al., 2006; Snider and Petters, 2008). Cabin heat also contributed to the drying of aerosol measured inside the aircraft.

PCASPs were calibrated with PSL particles with a refractive index (RI) of 1.59. For the data archive, a Mie scattering code was used to generate data at $\mathrm{RI}=1.55$, a value slightly more representative of continental aerosol. For this study, a second Mie scattering calculation was used to adjust size bins to an RI of $\mathrm{H}_{2} \mathrm{SO}_{4}$ (1.41). This is close to the volume weighted refractive index determined from nonrefractory components of sub micrometer size aerosol measured by the AMS $(\mathrm{RI}=1.46)$. Addition of retained water $(\mathrm{RI}=1.33)$ results in a lower refractive index, close to 1.41 .

Comparisons were made between aerosol volume determined by the SMPS and the two PCASPs. In order to match size ranges, volumes are calculated for $D_{p}$ between 0.11 and $0.44 \mu \mathrm{m}$. A linear regression of PCASP A volume vs. SMPS volume had a slope of 0.84 and $r^{2}=0.91$; for PCASP B the slope and $r^{2}$ were 0.98 and 0.93 , respectively. Agreement is well within the $30 \%$ uncertainty limits typically cited for PCASP and SMPS volume measurements. Volumes 
determined by PCASP A and B vary by only a few percent according to which unit is inside or outside of the aircraft.

PCASP and SMPS number distributions differed, primarily due to a low detection efficiency of small particles in the PCASP $\left(D_{p}<160 \mathrm{~nm}\right)$, which was confirmed only recently in a post-flight calibration of PCASP A. PCASP size distributions were adjusted to match those from the SMPS. A set of global adjustment factors to be applied to all PCASP data were determined by performing a linear regression between the SMPS and PCASP A and PCASP B for 15 size bins. All non-cloud data were used for these regressions. To test the normalization procedure, plots were made of PCASP vs. SMPS number concentration integrated over the overlap size range $110-440 \mathrm{~nm}$ (not shown). A least squares regression yields slopes of 0.95 and 0.96 for PCASP A and B vs. SMPS, respectively, both with an $r^{2}$ of 0.85 . By construction slopes should be close to unity. Scatter in the number comparisons is a measure of how well a single set of adjustment factors works in the differing environments encountered over 16 flights. Normalization resulted in an increase of total particle concentration by $41 \%$ and $18 \%$ from PCASP A and PCASP B, respectively.

By adjusting the PCASP data, we are relying on the SMPS as providing an intrinsically more accurate size distribution. The adjustment procedure allows for the determination of number concentrations and size distributions with 1s time resolution using PCASP data which on average agrees with the SMPS. Fast response aerosol number concentrations will prove useful in examining the anti-correlation between cloud droplets and interstitial aerosol.

\subsubsection{Cloud microphysics}

Cloud droplet number concentration (CDNC) was determined via a Cloud and Aerosol Spectrometer (CAS) probe manufactured by Droplet Measurement Technologies (DMT). Results were integrated over a diameter range between 2.5 and $50 \mu \mathrm{m}$. Cloud liquid water content (LWC) was measured with a Particle Volume Monitor (PVM, Gerber et al., 1994) and checked against a hot wire detector. Drizzle concentration was determined from a DMT Cloud Imaging Probe (CIP) which together with the CAS and hot wire detector are packaged together as a Cloud, Aerosol, and Precipitation Spectrometer (CAPS), mounted on a pylon off the nose of the G-1. Data has been archived at $0.1,1$, and $10 \mathrm{~Hz}$, and is available on request at 40 and in some cases $200 \mathrm{~Hz}$.

\subsection{Flights}

Figure 1 shows the 3-D sampling region of the G-1 during 16 of 17 research flights. An electrical failure on 18 Oct. limited data collection and that flight is not used in this study. Instrument status and flight times are tabulated in spreadsheet format on the same ftp site as the data. Flight duration was ap-

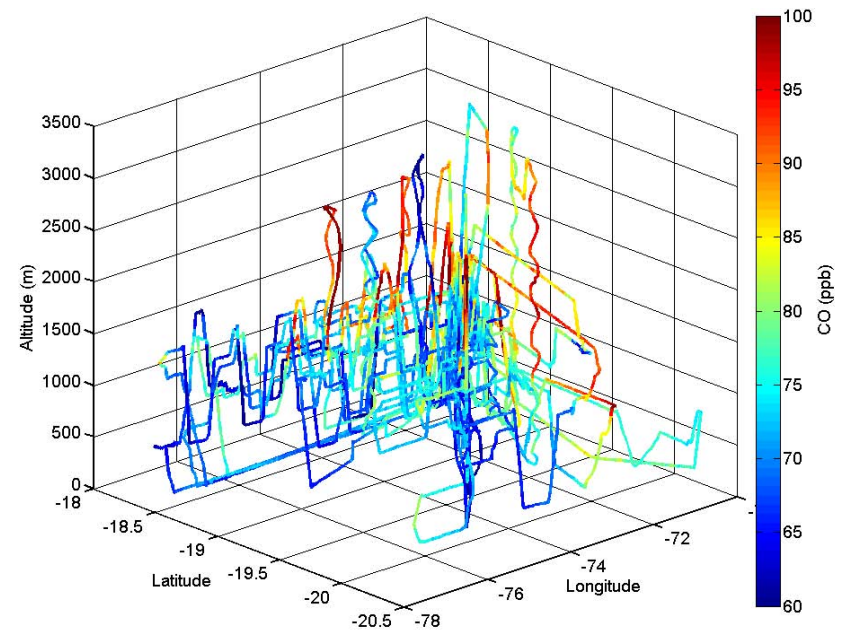

Fig. 1. Ground track of G-1 color coded by CO concentration. A portion of one flight south of -20.5 latitude not shown.

proximately $4 \mathrm{~h}$. Thirteen of 16 flights started between 08:57 and 10:20 (11:57 and 13:20 UTC).

Flight objectives were to determine the horizontal and vertical variability of cloud and aerosol properties. The range of the G-1 allowed for sampling between Arica at $70.3^{\circ} \mathrm{W}$ out over the Pacific to $78^{\circ} \mathrm{W}$, an E-W distance of $800 \mathrm{~km}$. Vertical sampling was primarily done via multiple transects at different altitudes or ascents and descents through clouds, and less often by porposing between cloud and above-cloud regions.

A typical flight track designed to sample longitudinal variations in cloud and aerosol properties is shown in Fig. 2. Because clouds thinned and sometimes disappeared due primarily to solar heating as the day progressed, the out bound leg was usually devoted to cloud sampling and the inbound leg to sampling in the boundary layer below cloud height. In order to examine interstitial aerosol, 102 constant altitude transects were identified in which the maximum liquid water content (LWC) was at least $0.1 \mathrm{~g} \mathrm{~m}^{-3}$. Often there were multiple transects in a single cloud separated by a step change in altitude of order tens of $m$ or greater. For many transects clouds were broken or occupied only a portion of the transect. One cloud on Flight 081028a (Fig. 2) is singled out as a case study to illustrate the anti-correlation between cloud droplet number concentration and interstitial aerosol found in all 102 cloud transects.

As indicated in Fig. 3, aerosol number concentration measured by SMPS was nearly the same on outbound and inbound legs, even though below-cloud measurements at a particular longitude could be separated by $500 \mathrm{~m}$ in altitude and more than $3 \mathrm{~h}$ in time (compare with Fig. 2). There are isolated occurrences in other flights of transects within $100 \mathrm{~m}$ of cloud base and in the mid to bottom MBL, in general indicating well mixed aerosol below cloud base. On average, 


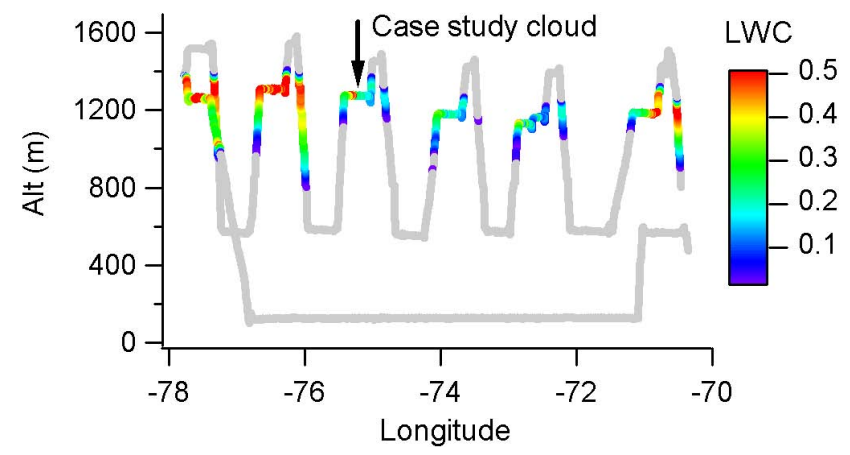

Fig. 2. Longitude-altitude cross section of flight track for $081028 \mathrm{a}$ color coded for cloud liquid water content in $\mathrm{g} \mathrm{m}^{-3}$. Cloud at $-75.2^{\circ} \mathrm{W}$ longitude is used to illustrate anti-correlation between cloud droplets and interstitial aerosol.

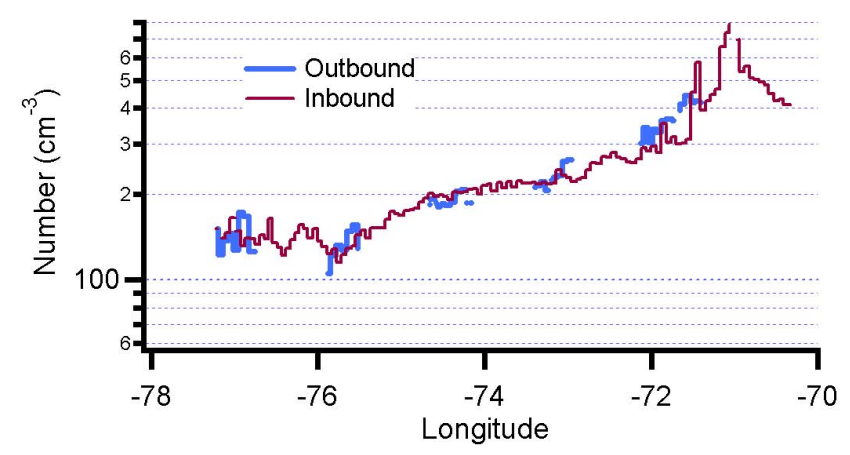

Fig. 3. Below cloud level SMPS measurement of number of particles with $D_{p}>75 \mathrm{~nm}$.

pre-cloud aerosol can be represented by low altitude samples collected at the same longitude. In addition, because horizontal gradients in composition are small, we allow air within $15 \mathrm{~km}$ of a cloud to be called pre-cloud. These approximations lead to scatter in relations between cloud and pre-cloud properties.

There were 3 intercomparison flights between the G-1 and C130, BAe-146 and Twin Otter that yielded data on LWC and CDNC (from a CDP or CAS probe). Results are summarized in Table 2. Intercomparisons were conducted with a several minute time separation between aircraft. Small differences in location, especially altitude, had a large influence on LWC. More significant are differences in CDNC where the G-1 values have to be reduced by 10,17 and $38 \%$ to match the C130, TO, and BAe146, respectively. Although the comparison with the BAe146 is based on a short sample through broken clouds, a particle balance between below cloud and in-cloud is consistent with the G-1 CDNC being approximately $20 \%$ too high - of the same order as published estimates of measurement uncertainty (Fountoukis et al., 2007). This factor also agrees with inter-platform differences in CDNC vs. longitude (not shown).

\section{Results}

Source regions for aerosol and trace gases have been analyzed by Allen et al. (2011) and Bretherton et al. (2010) by means of back trajectories calculated for marine boundary layer (MBL) at $950 \mathrm{hPa}$ and free troposphere (FT) at $850 \mathrm{hPa}$ starting from $20^{\circ} \mathrm{S}$ at distances from the shore varying from $70.5^{\circ} \mathrm{W}$ to $90^{\circ} \mathrm{W}$. Much of this work is pertinent to the longitudinal and vertical pollutant distribution measured by the G-1. Allen et al. (2011) and Bretherton et al. (2010) found that pollutants in the near coastal MBL could be explained by low altitude winds from the S and SE that intersected the Chilean coast. Trajectories terminating further offshore where pollution levels are lower tend to remain off shore, missing coastal emission sources. FT back trajectories were more diverse. In one population, descending air from the direction of Australia and South Asia carried pollutants to the VOCALS region. Another category of FT trajectory prevalent between the coast and $75^{\circ} \mathrm{W}$ were northerlies from Peruvian coastal regions. A contribution to the FT consisting of return coastal flow from the MBL is hypothesized by Allen et al. (2011) based on instances with high humidity and low $\mathrm{O}_{3}$.

\subsection{Spatial distributions}

Data have been segregated into marine boundary layer, precloud, in-cloud, and free tropospheric subsets, as defined in Table 3. Except when used in a general sense, the term "MBL" refers to non-cloud air below $800 \mathrm{~m}$ altitude. The particular definition of MBL can be recognized as it refers to, e.g. a region in which an average concentration or size distribution has been calculated. Below-cloud is that part of the data within the MBL (used as a general term) that is defined as being below clouds that were encountered on ascents and descents. Pre-cloud air is an approximation to the air actually ingested into a cloud. Because there are only a few instances of flight transects within cloud followed or preceded by a flight segment within $\sim 100 \mathrm{~m}$ of cloud base, several approximations are used in defining pre-cloud air, as given in Table 3 and described in Sect. 2.2. Clouds were located primarily between 800 and $1200 \mathrm{~m}$ altitude with cloud base and inversion height increasing with distance from the shore (Rahn and Garreaud, 2010; Bretherton et al., 2010).

Figure 4 shows frequency distributions of sub-micrometer aerosol number and volume concentration and $\mathrm{CO}$ and $\mathrm{O}_{3}$ mixing ratio as a function of longitude for the below cloud layer. Aerosol number concentration and volume decrease 2.3 and 3.6-fold, respectively between $70^{\circ}$ and $75^{\circ} \mathrm{W}$, the difference between number and volume appearing in the aerosol size distributions, presented below. There is a monotonic decrease in $\mathrm{CO}$ between $70^{\circ}$ and $75^{\circ} \mathrm{W}$ totaling $10 \mathrm{ppb}$, while $\mathrm{O}_{3}$ increases by $9 \mathrm{ppb}$ and continues to increase west of $75^{\circ}$ to the limit of our sampling at $78^{\circ} \mathrm{W}$. In contrast, $\mathrm{CO}$ and aerosol number and volume do not have a significant zonal 
Table 2. Cloud sampling intercomparisons.

\begin{tabular}{llllllll}
\hline Platform & Date & \multicolumn{3}{c}{ G-1 } & \multicolumn{3}{c}{ Other aircraft } \\
\hline & & CDNC & LWC & Time $^{1}$ & CDNC & LWC & Time $^{1}$ \\
TO & 26 Oct & 402 & 0.16 & $10: 47-10: 52$ & 335 & 0.14 & $10: 54-11: 04$ \\
C130 & 04 Nov & 226 & 0.10 & $11: 28-11: 35$ & 203 & 0.16 & $11: 25-11: 33$ \\
BAe-146 & 12 Nov & $47.3^{2}$ & $0.0065^{2}$ & $12: 49-12: 56$ & 29.3 & 0.0095 & $12: 45-12: 51$ \\
\hline
\end{tabular}

${ }^{1}$ rounded off to nearest minute. ${ }^{2}$ Maximum values $\sim 400 \mathrm{~cm}^{-3}, 0.1 \mathrm{~g} \mathrm{~m}^{-3}$, in-cloud for $\sim 1 \mathrm{~min}$.

Table 3. Definition of atmospheric layers.

\begin{tabular}{lllll}
\hline Variable $^{1}$ & \multicolumn{3}{c}{ Data Subset } \\
\hline & marine boundary layer & pre-cloud & in-cloud & above-cloud \\
Altitude $(\mathrm{m})$ & $<800$ & below and within $15 \mathrm{~km}$ of cloud & $>600$ & $>1200$ \\
$\mathrm{RH}(\%)$ & $\mathrm{n} / \mathrm{a}$ & $<90$ & $\mathrm{n} / \mathrm{a}$ & $\mathrm{n} / \mathrm{a}$ \\
Theta $\left({ }^{\circ} \mathrm{C}\right)$ & $\mathrm{n} / \mathrm{a}$ & $\mathrm{n} / \mathrm{a}$ & $\mathrm{n} / \mathrm{a}$ & $>22$ \\
$\mathrm{LWC}\left(\mathrm{g} \mathrm{m}^{-3}\right)$ & $<0.01$ & $<0.01$ & $>0.02, \mathrm{LWC}_{\mathrm{avg}}>0.05$ & $<0.01$ \\
\hline
\end{tabular}

${ }^{1}$ Condition applies to each 1s time period within averaging time, except for $\mathrm{LWC}_{\text {avg }}$ which is an average value over a 1 minute SMPS scan.

gradient west of $75^{\circ}$. Median concentrations in the free troposphere are also given in Fig. 4. Concentrations are highest near the coast except for $\mathrm{O}_{3}$. Relative to the marine boundary layer, $\mathrm{CO}$ and especially $\mathrm{O}_{3}$ have a greater concentration in the free troposphere. Particle volume decreases severalfold with altitude but number concentration decreases only marginally, a result consistent with size distributions shown in a following section. The broad covariance between MBL and FT aerosol and trace gases suggest coupling between these atmospheric layers.

Even though the sampling region of the G-1 was primarily north of the $20^{\circ} \mathrm{S}$ corridor reported on by Allen et al. (2011), there is excellent agreement in longitudinal structure in the MBL and FT for the 3 quantities that can be directly compared: $\mathrm{O}_{3}, \mathrm{CO}$, and $\mathrm{CN}$ (10 nm lower limit from CPC 3010 on BAe146, $15 \mathrm{~nm}$ from SMPS on G-1). $\mathrm{SO}_{2}$ concentrations were below our detection limit of $\sim 0.2 \mathrm{ppb}$ except for a few near coast measurements, not surprising in a cloud covered MBL where there is opportunity for aqueous phase reaction with $\mathrm{H}_{2} \mathrm{O}_{2}$. With a more sensitive instrument, Allen et al. (2011) report mean $\mathrm{SO}_{2}$ concentrations of 20-30 ppt, with higher values near the coast and concentrations approaching $1 / 2 \mathrm{ppb}$ in a few discrete layers at $2-3 \mathrm{~km}$ altitude. The general picture based on longitudinally dependent $\mathrm{SO}_{2}$ and aerosol sulfate measurements is that even near the shore, within the MBL, air masses had a high sulfate to $\mathrm{SO}_{2}$ molar ratio indicating that with respect to sulfur theses air masses were aged.

Frequency distributions as a function of altitude have been constructed by dividing the data set into altitude bins as shown in Fig. 5. Data points in and out of clouds are in- cluded for $\mathrm{CO}$ and $\mathrm{O}_{3}$, but points with $\mathrm{LWC}>0.01 \mathrm{~g} \mathrm{~m}^{-3}$ are excluded for aerosol number and volume. Because samples are not uniformly distributed in longitude or altitude, there are biases in constructing these vertical profiles. As can be seen from Fig. 1, high altitude points are primarily east of $74^{\circ}$. Also, according to Fig. 5f, data points between 400$800 \mathrm{~m}$ are closer to the shore than those in the lower altitude bin (100-400 m) thereby accounting for aerosol volume increasing with altitude in the two low altitude bins (Fig. 5b). The vertical structure shown in Fig. 4, in general, appears more pronounced than that shown in Fig. 5. This is partly an artifact caused by sampling inhomogeneities mentioned above. There is also a real difference in the data sets as the FT data in Fig. 4 incorporates the requirement that potential temperature, $\theta$, exceed $22^{\circ} \mathrm{C}$, a constraint that insures separation between below and above cloud aerosol size spectra.

Figure 5e shows that in each of the three above cloud altitude bins, dew point varies by about $40^{\circ} \mathrm{C}$, indicating that at a given altitude in the FT air masses with very different histories are being sampled. As dew point is controlled by the maximum altitude to which an air parcel is lifted, lower dew points indicate air masses that subsided from the middle or upper troposphere, whilst higher dew points indicate air masses that have a boundary layer origin. The association between dew point and air mass origin prompts us to examine aerosol and trace gas concentration as a function of dew point in Fig. 6. A qualitative correspondence between layers defined according to dew point and those defined according to altitude is that the below-cloud part of the MBL corresponds to the two bins with highest dew point $\left(>10^{\circ} \mathrm{C}\right)$, the cloud layer has dew point between 6 and $10^{\circ} \mathrm{C}$, and the three 

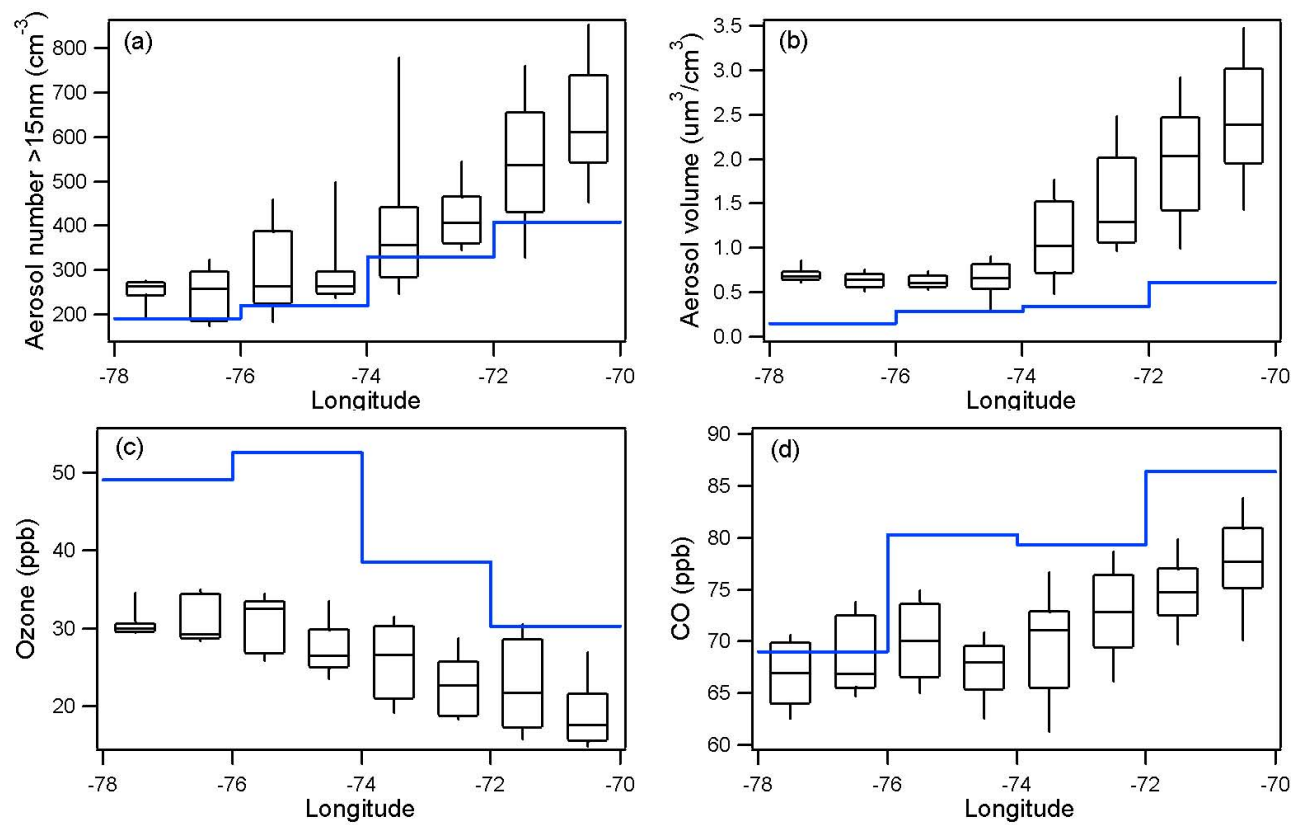

Fig. 4. Box plot showing frequency distribution of measurements in the MBL below $800 \mathrm{~m}$ of (a) aerosol number concentration and (b) volume measured by SMPS, (c) $\mathrm{O}_{3}$, and (d) CO. Box indicates the 25th to 75th percentile range with line for median. Whiskers show 10 th and 90th percentile values. Blue lines indicate the median values of FT observation divided into two degree longitude bins.
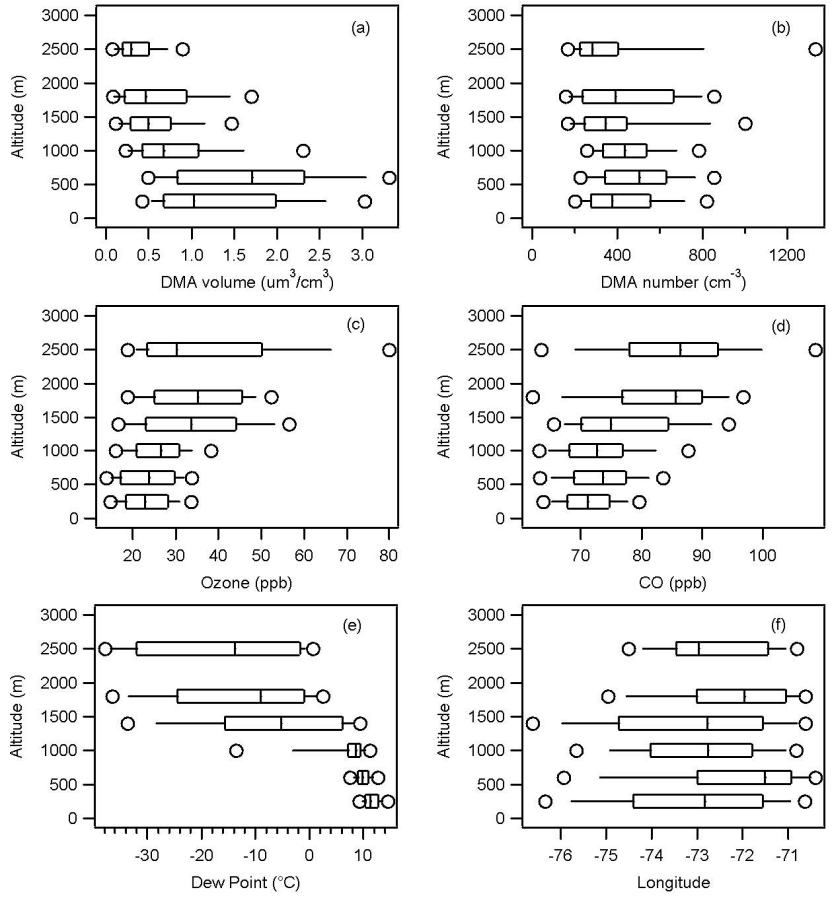

Fig. 5. Frequency distribution as a function of altitude. Box indicates the 25th to 75 th percentile range with line for median. Whiskers show 10th and 90th percentile values. Circles are 5th and 95 th percentile. Altitude bins are $100-400 \mathrm{~m}, 400-800 \mathrm{~m}, 800-$ $1200 \mathrm{~m}, 1200-1600 \mathrm{~m}, 1600-2000 \mathrm{~m}$, and above $2000 \mathrm{~m}$. above cloud layers are represented by three dew point ranges between 6 and $-40{ }^{\circ} \mathrm{C}$.

For water soluble substances with a surface source, the decrease in temperature and specific humidity with altitude is an effective cold trap preventing upward transport and leading to a qualitative proportionality between accumulation mode aerosol and water vapor (Kleinman and Daum, 1991). Aerosol volume decreases with dew point, in this case by a factor of 6 , due to precipitation removal of particles large enough to act as $\mathrm{CCN}$ whilst insoluble substances such as $\mathrm{CO}$ and $\mathrm{O}_{3}$ are not affected. Particle number concentration does not decrease to the same extent because most of the particles in dry air are too small to act as CCN. Trends in the number concentration of larger particles, say $D_{p}>0.1 \mu \mathrm{m}$, more nearly follow aerosol volume.

Ozone is seen to increase in drier air as expected for a gas with an upper atmospheric source. Also contributing to the $\mathrm{O}_{3}$ gradient is surface deposition and photochemical destruction by $\mathrm{O}_{3}+h v \rightarrow \mathrm{O}\left({ }^{1} \mathrm{D}\right) ; \mathrm{O}\left({ }^{1} \mathrm{D}\right)+\mathrm{H}_{2} \mathrm{O} \rightarrow 2 \mathrm{OH}$, which proceeds more rapidly in moist air near the surface (Ayers et al., 1992). Given a long enough residence time, near surface $\mathrm{O}_{3}$ concentrations can approach zero as seen by Kley et al. (1996) in the remote Pacific. Although photochemical destruction of $\mathrm{O}_{3}$ in the MBL is expected, concentrations in the limited geographic area covered by the G-1 increase with distance from the coast. The VOCALS region, unlike the remote Pacific, is characterized by strong subsidence and it is likely that the source of $\mathrm{O}_{3}$ in the MBL towards the west is subsidence from the FT. Indeed, $\mathrm{O}_{3}$ from the FT is used as an 

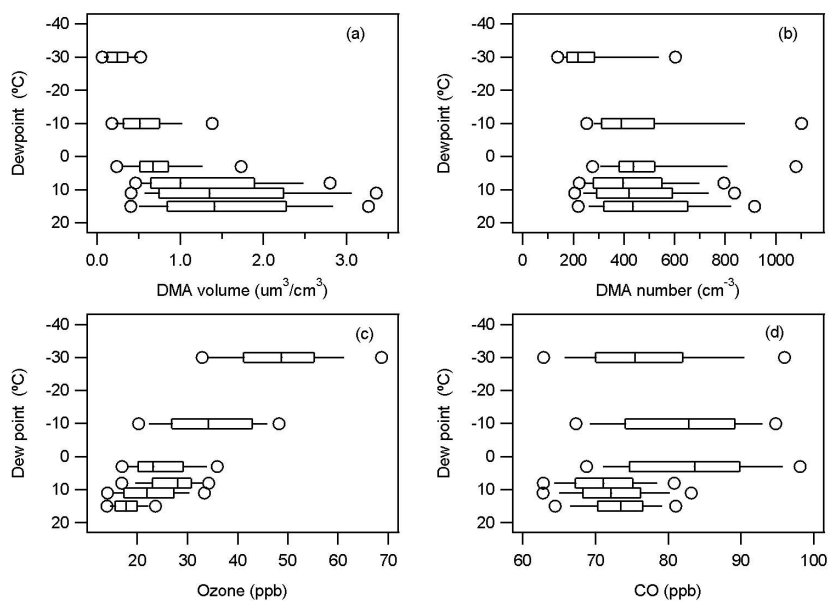

Fig. 6. Frequency distribution as a function of dew point. Box plot format same as in Fig. 5. Dew point bins are 16 to $12{ }^{\circ} \mathrm{C}$, 12 to $10^{\circ} \mathrm{C}, 10$ to $6^{\circ} \mathrm{C}, 6$ to $0^{\circ} \mathrm{C}, 0$ to $-20^{\circ} \mathrm{C},-20$ to $-40^{\circ} \mathrm{C}$. Qualitatively, the first 2 bins are below cloud, the third bin in the cloud layer, and the driest 3 bins above cloud.

inert tracer to quantify cloud top entrainment (e.g. Faloona et al., 2005). Aerosol particles will be entrained as a component of $\mathrm{FT} \mathrm{O}_{3}$ containing air. Although large particles in the FT are fewer than in the MBL (Sect. 3.2, following), they can, as shown by Clarke et al. $(1996,1997)$, provide CCN to replace those lost by drizzle - a process of particular importance in the drizzled out Pocket of Open Cell (POC) regions further west than the G-1 sampled (Wood et al., 2011).

In the MBL, $\mathrm{CO}$ is anti-correlated with $\mathrm{O}_{3}$ consistent with the oppositely directed east-west trends shown in Figs. 4c and d. Emission sources are located on land which lends some logic to $\mathrm{CO}$ concentrations being highest near the shore but does not address the near-shore $\mathrm{O}_{3}$ which not only is low but is also anticorrelated with $\mathrm{CO} . \mathrm{CO}-\mathrm{O}_{3}$ anticorrelations of the type observed in winter by Parrish et al. (1998) do not seem relevant in the low $\mathrm{NO}_{\mathrm{x}}$ VOCALS region. Allen et al. (2011) suggest the possible effects of fresh emissions but also note that a transport process may be responsible. An explanation for the low near-shore $\mathrm{O}_{3}$ may have to await process analysis of chemical transport model results (Yang et al., 2011).

The anti-correlation between $\mathrm{CO}$ and $\mathrm{O}_{3}$ disappears at the 0 to $-20^{\circ} \mathrm{C}$ dew point level and in the driest air is replaced with a significant positive correlation due to long range transport of pollution plumes. An extreme example occurred on Flight $081025 \mathrm{a}$ and is identified on Fig. 7. The polluted layer was at $74.5^{\circ} \mathrm{W}$ between 2300 and $2500 \mathrm{~m}$ altitude. Dew point at $-40^{\circ} \mathrm{C}$ was among the driest observed. Insoluble pollutants, $\mathrm{CO}$ and $\mathrm{O}_{3}$ averaged 115 and $83 \mathrm{ppb}$, the highest levels observed during the campaign. Aerosol number and volume were several-fold less than at lower altitude but were the highest values observed in such dry air. Ten day back trajectories generated from the HYSPLIT model (Draxler and
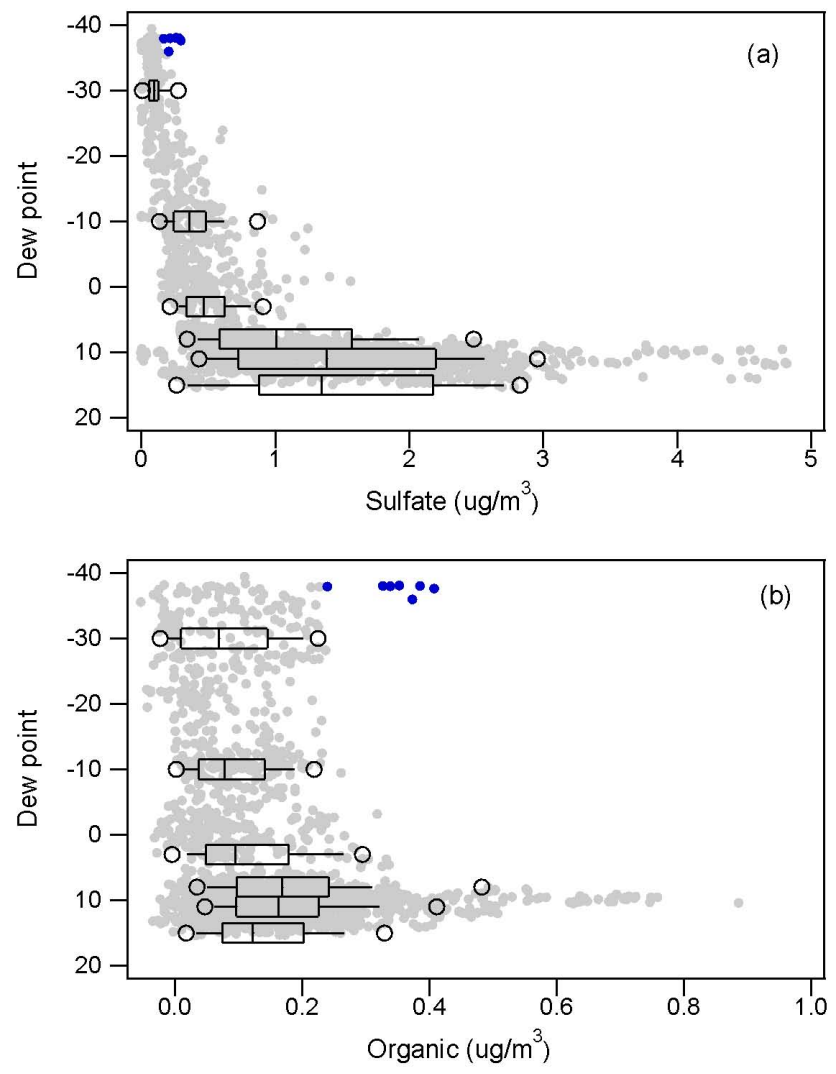

Fig. 7. Box plot showing frequency distributions for (a) sulfate and (b) organic aerosol measured with the AMS as a function of dew point. Box plot has same format as in Fig. 5. Each gray point represents data averaged over a $\sim 60 \mathrm{~s}$ DMA scan. Data points with LWC $>0.01 \mathrm{~g} \mathrm{~m}^{-3}$ are excluded. Blue points are $7 \mathrm{~min}$ of measurements in an organic rich plume on 25 October. An indication of the AMS signal to noise is provided by the small number and magnitude of points with negative concentration.

Rolph, 2010) descend from high altitude ( $>7000 \mathrm{~m}$ ) over the Pacific but are inconclusive regarding the origin of this air mass. As CO definitely has a boundary layer source, these descending air parcels maintain a chemical record of a prior boundary layer residence.

In order not to distort statistical relations by a single high concentration plume, correlations for data with dew point between -20 and $-40^{\circ} \mathrm{C}$ have been calculated with and without data from 25 October. With the 25 October plume, a reduced major axis least squares regression yields a $\mathrm{CO}$ to $\mathrm{O}_{3}$ ratio of 1.0 with an $r^{2}$ of 0.68 . Removing the 25 October data yields a $\mathrm{CO}$ to $\mathrm{O}_{3}$ ratio of 1.2 with an $r^{2}$ of 0.41 . Both values indicate very efficient $\mathrm{O}_{3}$ production and/or loss of $\mathrm{O}_{3}$ in transport as compared with surface observations that have a $\mathrm{CO} / \mathrm{O}_{3}$ ratio a factor of 3 lower (Parrish et al., 1998). The 25 Oct. plume shows up in the concentrations of aerosol sulfate and even more in organic aerosol (Fig. 7). A linear regression between organic aerosol and $\mathrm{CO}$ gives a ratio of $7.2 \mu \mathrm{g} \mathrm{m}^{-3}$ per ppm CO $\left(r^{2}=0.56\right)$. A similar ratio of $6.9 \mu \mathrm{g} \mathrm{m}^{-3}$ per 
ppm CO is obtained without data from 25 October. These values are an order of magnitude lower than found in polluted boundary layer air masses after about one day of photochemical processing (Kleinman et al., 2008), indicating precipitation removal of aerosol.

In addition to the $\mathrm{CO}$ plumes observed in the driest air there are observations of high $\mathrm{CO}(>80 \mathrm{ppb})$ concentration, located over a range of altitudes with dew points between 0 and $6^{\circ} \mathrm{C}$ (i.e. in the bin just above the cloud layer). $\mathrm{CO}$ in these cases is anti-correlated with $\mathrm{O}_{3}$. HYSPLIT back trajectories intercept or come close to the Peruvian coast in agreement with wind measurements presented by Bretherton et al. (2010) and Rahn and Garreaud (2010). Bretherton et al. (2010) note that heating of the Andean slope mixes moisture into a layer that becomes the lower free troposphere when advected over the Pacific. High concentrations of $\mathrm{CO}$ in the moist above cloud layer are further evidence of the upward mixing of continental boundary layer air. The next driest bin in Fig. 6 also has data points with high CO. Here the anti-correlation between $\mathrm{CO}$ and $\mathrm{O}_{3}$ has changed into a lack of correlation.

Concentrations of aerosol sulfate and organics both decrease with altitude (Lee et al., 2011) or dew point (Fig. 7). There is a selective reduction in aerosol sulfate in dry air which could reflect a greater solubility in cloud droplets and propensity for wet removal, relative to organics, and/or a different mixture of sources affecting boundary layer and free tropospheric air. Whereas the organic to sulfate ratio is $\sim 0.1$ in the marine boundary layer it increases to above 0.5 in the driest air and is greater than 1 in the plume encountered on 25 October. Absorption measurements were examined for information on light absorbing carbon aerosol. Except for isolated plumes and areas near land, aerosol absorption was too low to reliably quantify with a median value of $0.6 \mathrm{Mm}^{-1}$ in the boundary layer and $0.4 \mathrm{Mm}^{-1}$ above.

\subsection{Aerosol size distribution}

Aerosol size distributions measured with the SMPS are shown as a function of longitude in Fig. 8 for the below cloud layer and free troposphere. Below cloud aerosol has a characteristic two mode structure separated by a minimum. As described by Hoppel et al. (1986) this minimum is the result of a selective activation of larger aerosol particles in the cloud forming process. Aqueous phase chemistry, principally the oxidation of $\mathrm{SO}_{2}$ to sulfate adds solute mass. Upon cloud evaporation, larger aerosol particles that had been activated create an accumulation-size mode (sometimes called a droplet mode) that is distinct from the smaller aerosol particles that have not increased in mass by aqueous phase chemistry. Composition measurements reported by Lee et al. (2011) show that sub micron size aerosol is primarily partially neutralized $\mathrm{H}_{2} \mathrm{SO}_{4}$, consistent with a formation route by aqueous phase oxidation of $\mathrm{SO}_{2}$. It would be expected that the droplet mode contains a higher ratio of sulfate to or-
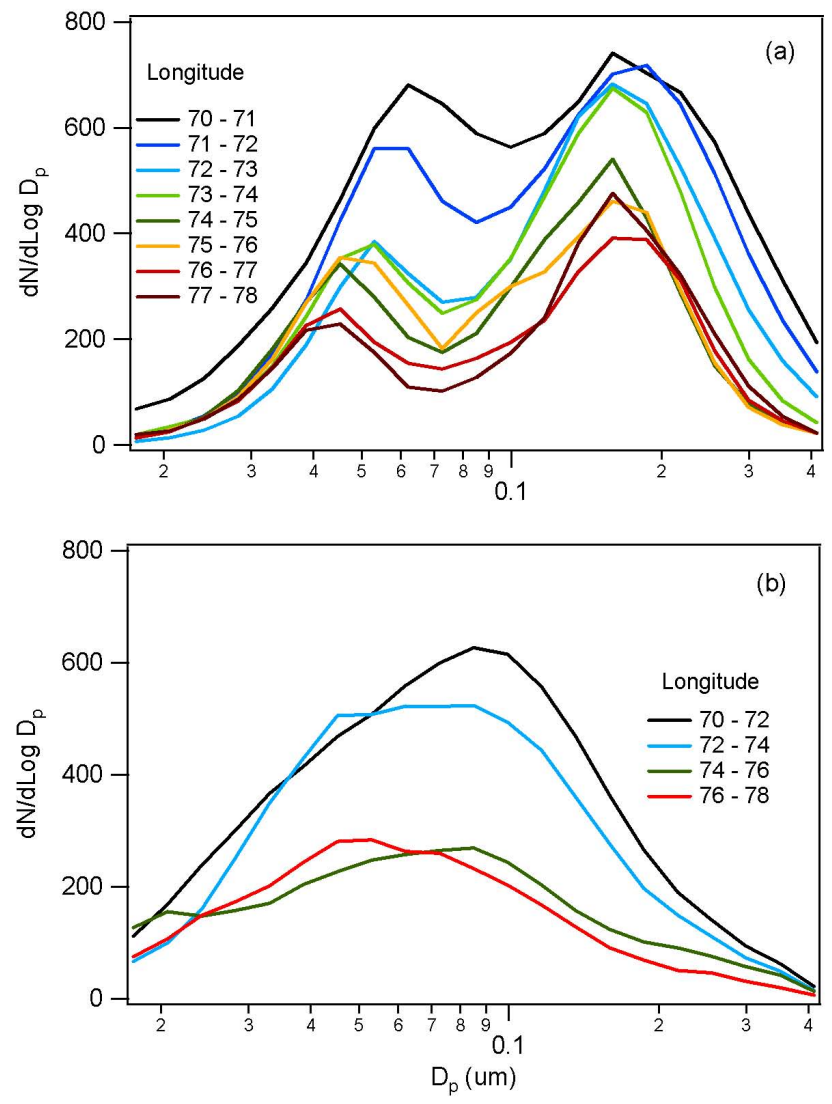

Fig. 8. Aerosol size distribution measured with SMPS (a) in the MBL below $800 \mathrm{~m}$ and (b) above cloud layer.

ganics than the Aitken mode. This, however, could not be tested using AMS size distributions because the volume of the Aitken mode was too small to quantify. With increasing distance from the shore, Fig. 8 shows that the droplet mode contains an increasing fraction of the total aerosol. At the same time, the droplet mode becomes narrower with a decreasing proportion of larger particle $\left(D_{p}>300 \mathrm{~nm}\right)$. The droplet mode size is nearly invariant $\left(D_{p}=160-185 \mathrm{~nm}\right)$ but the Hoppel minimum diameter and the Aitken mode size move to lower values. A possible mechanism for the movement of the Hoppel minimum diameter and Aitken mode to a smaller size is that aerosol concentrations are lower further from the coast, which in the presence of a fixed vertical velocity results in smaller particles being activated. In contrast, free tropospheric aerosol is predominately unimodal with a mode size between that for Aitken and accumulation modes observed in the MBL.

Size distributions of aerosol particles as functions of dew point are shown in Fig. 9. Particles in the boundary/cloudy layer with $T_{d}>6{ }^{\circ} \mathrm{C}$ are seen to have a bimodal distribution characteristic of cloud processing. Layers with dew point between -20 and $6{ }^{\circ} \mathrm{C}$ have on average a broad size distribution centered at $80-100 \mathrm{~nm}$. Most often, the individual size 


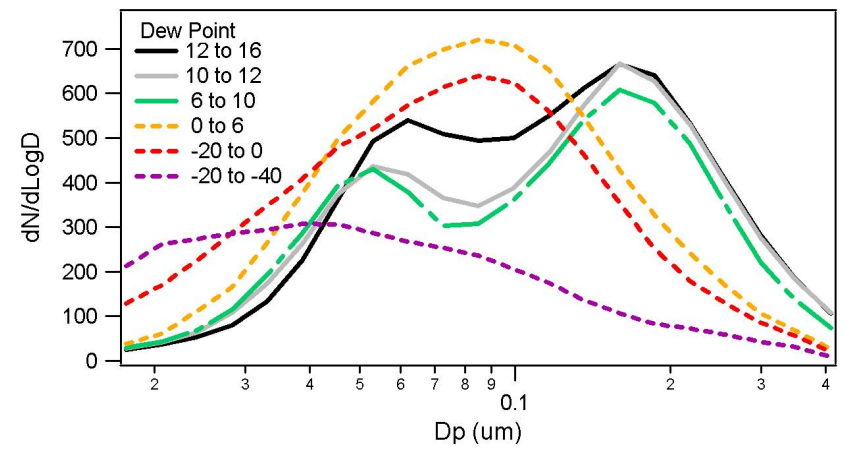

Fig. 9. Aerosol size distribution in cloud-free air from the SMPS as a function of dew point. Qualitatively, dew points from 10 to $16^{\circ} \mathrm{C}$ are located below cloud, $6-10^{\circ} \mathrm{C}$ is the cloud layer, and dew points below $6^{\circ} \mathrm{C}$ are in the free troposphere, above cloud.

distributions are close to unimodal but when compared with a single log normal fit, have tails at large and small diameter. Though the apparent widths in the dry subsets shown in Fig. 9 are in part due to averaging over samples with different mode diameters between $\sim 40$ and $110 \mathrm{~nm}$, the individual distributions are wide with a median geometric standard deviation of 1.81 At the lowest dew points there are an increasing number of samples with an additional smaller, nucleation mode, not fully resolved by the SMPS. As a consequence, the average aerosol size becomes smaller.

\subsection{First indirect effect}

In Fig. 10, pre-cloud aerosol (Table 3) with $D_{p}>100 \mathrm{~nm}$ are compared with CDNC. As discussed below, $100 \mathrm{~nm}$ is a representative critical diameter for activation given composition, size spectra, and updraft velocity. Cloud droplet concentrations have been multiplied by 0.8 which brings the G-1 measurements into better agreement with the intercomparison data given in Table 2. An increase in CDNC with aerosol as shown in Fig. 10 is a necessary condition for the first indirect effect but as others have noted it is more difficult to make an association with an increase in cloud albedo (Twohy et al., 2005 and references therein). It can be seen that additional aerosol results in a less than proportionate increase in cloud droplets, a result that has been observed by other groups (e.g., Leaitch et al., 1986; Ramanathan, 2001; Twohy et al., 2005).

An alternate explanation for the less than proportionate increase in cloud droplets has been offered by Lance (2011) based on a careful analysis of CDP (Cloud Droplet Probe) and CAS probes showing a high incidence of "extended" coincidence errors at CDNC as low as $200 \mathrm{~cm}^{-3}$ (Lance et al., 2010). As the CDP and CAS probes are widely used to provide cloud droplet data pertinent to many cloud microphysics problems, systematic errors must be taken seriously. In the context of the present study, simulations of coincidence errors (Fig. 13 of Lance et al., 2010) showed that undercounting at $\mathrm{CDNC}>200 \mathrm{~cm}^{-3}$, caused a departure from a lin-

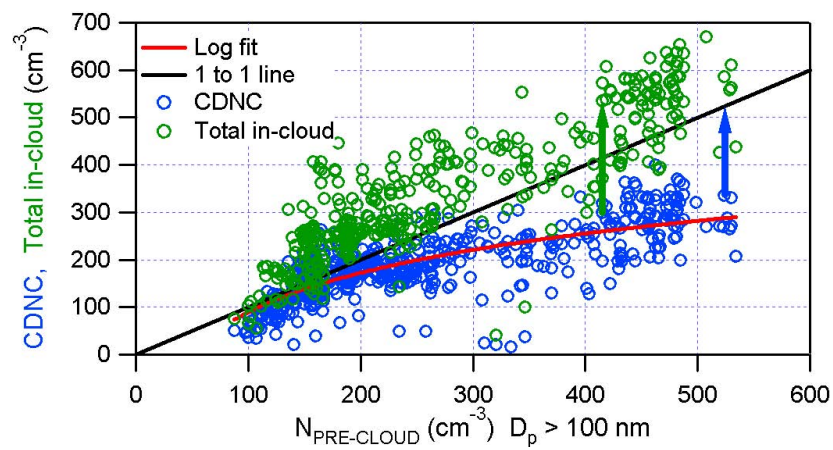

Fig. 10. Cloud droplet number concentration (CDNC) in blue and total in-cloud particle concentration $(\mathrm{CDNC}+$ measured interstitial aerosol) in green as a function of pre-cloud aerosol. CDNC has been multiplied by 0.8 . Aerosol concentration, measured with an SMPS, is the sum of particles with $D_{p}>100 \mathrm{~nm}$. Each data point is $\sim$ one minute of in-cloud data and an average of several minutes of pre-cloud aerosol data. Broken clouds are eliminated. Equation of red line is CDNC $=-463+276 \log _{10}\left(\mathrm{~N}_{\mathrm{PRE}-\mathrm{CLOUD}}\right)$. On the black 1 to 1 line, the total number concentration of in-cloud particles (aerosol + cloud droplets) is equal to the number concentration of pre-cloud aerosol. Blue data points above the black line are due to activation of aerosol smaller than $100 \mathrm{~nm}$, imprecision in indentifying pre-cloud air, or measurement inaccuracies. Green symbols denoted as "Total in-cloud" are the sum of coincident measurements of CDNC plus interstitial aerosol with $D_{p}>100 \mathrm{~nm}$. An illustration of $\mathrm{N}_{\mathrm{INT}}$ by the number balance and direct observation method is given by the lengths of the blue and green arrows, respectively. The blue arrow starts at a blue point with specified CDNC and ends on the 1 to 1 line. The green arrow starts at another blue point with specified CDNC and ends on the corresponding green Total in-cloud point.

ear response that appears similar to the VOCALS data in our Fig. 10. The same simulations showed positive errors in volume mean diameter and, for $D_{p}<20 \mu \mathrm{m}$, positive errors in LWC (Figs. 12 and 15, respectively). Field observations in warm clouds were in agreement with simulations, indicating that LWC derived from the CDP was approximately a factor of two higher than that determined from a hot wire detector at a CDNC of $600 \mathrm{~cm}^{-3}$ (Fig. 7). It is only the disagreement in LWC that we have the measurements to address. Data presented in Kleinman et al. (2011) have been rearranged to show the fractional bias in liquid water concentration as a function of CDNC. From a least squares regression, the fractional bias for the CAS relative to LWC from the hot wire and Gerber probes is $-3.7 \%$ and $-5.4 \%$, respectively, at $\mathrm{CDNC}=600 \mathrm{~cm}^{-3}$. These results do not rule out errors in the G-1 measurements of CAS droplet size and number, but the nearly exact cancellation in the calculation of LWC seems improbable. With diagnostics limited to LWC, we have no explanation for the difference between the G-1 results and those presented by Lance et al., (2010) and Lance (2011) except to note the comment in the later reference concerning changes to the CAS probe. 


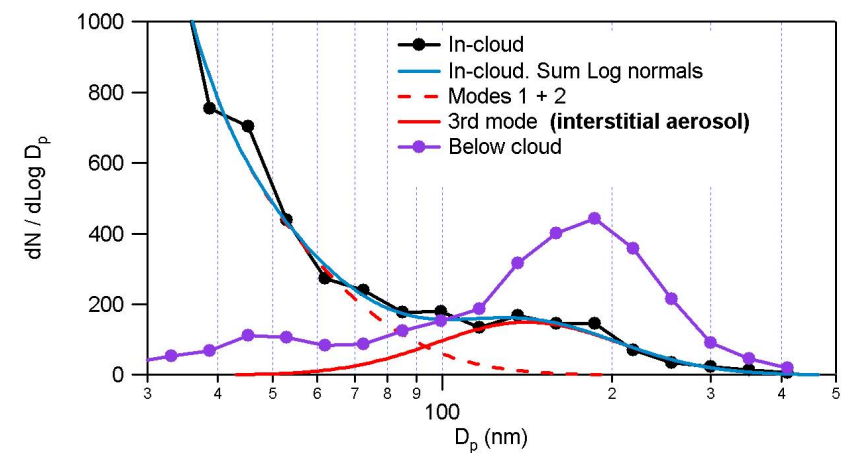

Fig. 11. A $60 \mathrm{~s}$ in and below-cloud SMPS size distributions from the 28 October case study cloud. Black circles are in-cloud SMPS measurements which have been fit to a sum of $3 \log$ normals (blue line). The 3 rd mode is identified as interstitial aerosol. The dashed red line indicates the sum of the 2 smaller modes which in this case make a minor contribution to number concentration in the PCASP size range. For comparison the purple trace is pre-cloud aerosol. Points in the SMPS size distributions are joined by straight lines for easy visualization.

\subsection{In-cloud aerosol}

Aerosol particles that are measured coincident with cloud liquid water at $1 \mathrm{~s}$ time resolution will be called interstitial. For the purpose of defining an interstitial number concentration, $\mathrm{N}_{\text {INT }}$, the minimum diameter is $110 \mathrm{~nm}$ for PCASP measurements (lower limit of detection) or $100 \mathrm{~nm}$ for the SMPS, as in Fig. 10.

\subsubsection{Measurement artifacts}

Cloud droplet shatter contributes to $\mathrm{N}_{\text {INT }}$. In-cloud SMPS size spectra show extremely high concentrations of small particles, i.e. $10^{3}$ to more than $10^{4}$ particles $\mathrm{cm}^{-3}$ smaller than $50 \mathrm{~nm}$ diameter. Similar concentrations of small particles in-cloud have been previously observed and attributed to droplet shatter (e.g., Hudson and Frisbie, 1991; Clarke et al., 1997; Weber et al., 1998). Given extremely high concentrations of small particles, the much less numerous accumulation mode aerosol do not stand out. Rather, they appear as a shoulder or sometimes a bump in the size distribution that is quantifiable as a separate mode by fitting the distribution to a sum of log normals. A single example from a Case Study presented below is given in Fig. 11. In this case, a small percentage of in-cloud particles large enough to be detected by the PCASP are part of a tail on the shatter distribution. A majority of larger particles appear to be part of a mode that is distinct from the shatter size distribution. According to the log normal fits for all of the incloud data with $L W C>0.1 \mathrm{~g} \mathrm{~m}^{-3}$, the average shatter contribution to aerosol with $D_{p}>100 \mathrm{~nm}$ and $150 \mathrm{~nm}$ is $19 \%$ and $10 \%$, respectively (calculated as summed shatter divided by summed accumulation mode, with summation over all SMPS

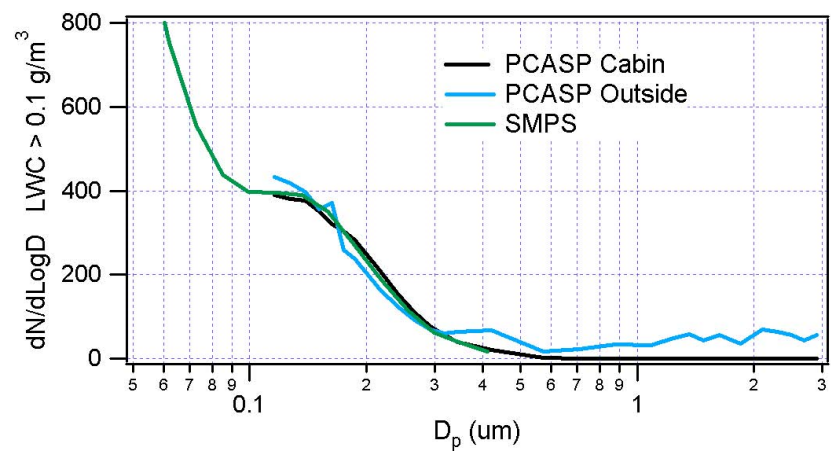

Fig. 12. In-cloud aerosol size distribution with $\mathrm{LWC}>0.1 \mathrm{~g} \mathrm{~m}^{-3}$ averaged over campaign.

scans satisfying cloud criteria). Excluding the shatter, the inside-cabin PCASP shows a mode with a geometric mean diameter of $140 \mathrm{~nm}$, which is smaller than the mean diameter of the accumulation mode in the MBL (Fig. 8a). Although, the log normal fits are suggestive, there is no a priori reason why cloud droplet shatter should have this functional form, which contributes uncertainty to the quantitative apportionment of larger particles between droplet shatter and interstitial aerosol.

Cloud droplet evaporation caused by heating in the PCASP or aerosol inlet can contribute to aerosol detected incloud. Complete or partial evaporation is possible. As shown in Fig. 12, the signature of partial evaporation is a population of large aerosol particles with $D_{p}$ extending from $\sim 350 \mathrm{~nm}$ to $3 \mu \mathrm{m}$ (Leaitch et al., 1996). These larger particles without a modal structure are only observed with the outside mounted PCASP and are in contrast to the almost complete absence of particle larger than $600 \mathrm{~nm}$ observed in clear air. Bringing air into the cabin of the $\mathrm{G}-1$ yields a $5^{\circ} \mathrm{C}$ temperature increase which is calculated to evaporate most cloud droplets within one second (R. McGraw, personal communication, 2011), a time scale competitive with aerosol impaction on a bend in the sampling line. Complete evaporation of cloud droplets is a large potential source of interstitial aerosol. However, a comparison of the in-cabin PCASP and SMPS with the nose mounted PCASP shows a similar size distribution aside from the larger particles noted above. Some degree of similarity might be expected as both PCASPs have sites where droplets can impact and shatter and both have adiabatic heating along with active heating from a de-icer (Strapp et al., 1992). With increasing LWC or with increasing cloud droplet size, the outside PCASP concentration increases relative to the incabin measurement.

\subsubsection{Magnitude of interstitial aerosol}

The number concentration of interstitial aerosol with $D_{p}>100 \mathrm{~nm}, \mathrm{~N}_{\mathrm{INT}}$, can be obtained indirectly from a number balance between pre-cloud and in-cloud particles, based 

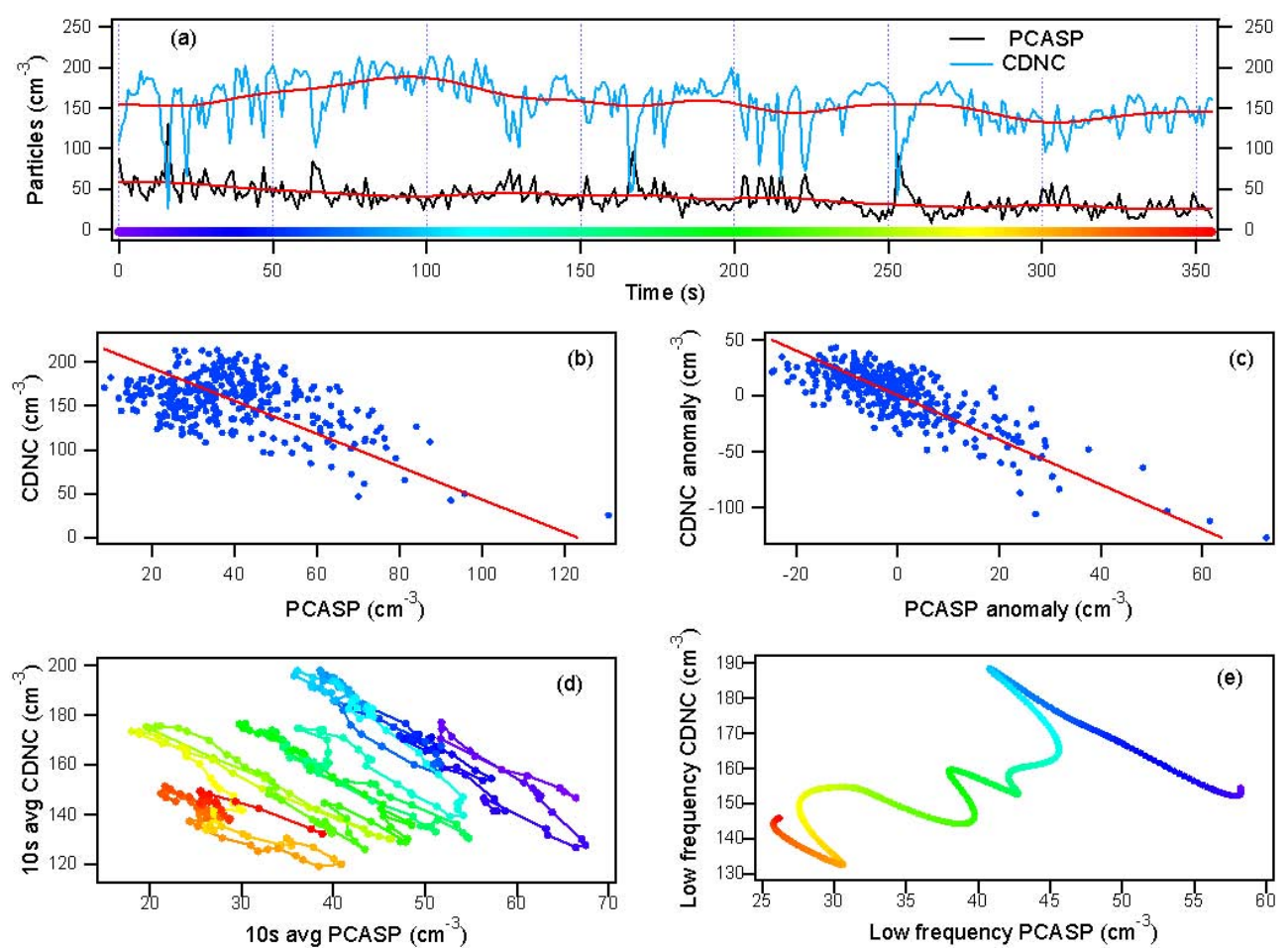

Fig. 13. Interstitial aerosol and cloud droplet number in cloud sampled on 28 October (see Fig. 2) (a) Time series of aerosol from insidecabin PCASP and CDNC at $1 \mathrm{~Hz}$ and with $400 \mathrm{~s}$ binomial smoothing (red lines). Color bar indicates time in seconds. (b) Scatter plot of $1 \mathrm{~Hz}$

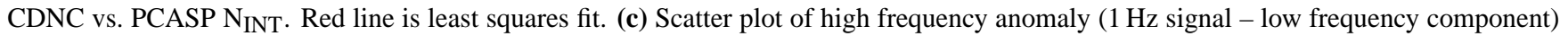

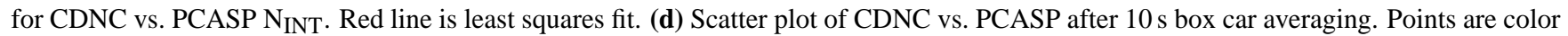
coded according to scale in (a) and are joined to indicate continuity. Note that the points fit within the envelope of points in (b) but appear more spread out because of a change of scale. (e) Scatter plot of CDNC vs. PCASP after $400 \mathrm{~s}$ binomial smoothing. Points are color coded as in (a) and (d).

on the assumption that aerosol smaller than $100 \mathrm{~nm}$ are not activated. $\mathrm{N}_{\text {INT }}$ obtained by number balance is illustrated for a single cloud data point by the blue arrow in Fig. 10. The fraction of in-cloud particles that are interstitial, defined using average values in the expression $\left(\mathrm{N}_{\mathrm{INT}} /\left(\mathrm{N}_{\mathrm{INT}}+\mathrm{CDNC}\right)\right.$ ), is 0.27. As in Fig. 10, CDNC incorporates a factor of 0.8, based on the assumption that actual CDNC are lower than reported (see Sect. 3.3). As can be seen from the red line representing a fit to the pre-cloud aerosol, most particles not activated are at higher aerosol concentration, where competition for water vapor is more likely.

$\mathrm{N}_{\text {INT }}$ can also be directly measured, again using the criterion that $D_{p}>100 \mathrm{~nm}$. This is illustrated in Fig. 10 for a single cloud data point by a green arrow which connects a pre-cloud aerosol concentration with the corresponding sum of cloud droplets plus measured interstitial aerosol. Based on the in-cloud aerosol measurements, the total number of in-cloud particles is, on average, a factor of 1.29 greater than the pre-cloud aerosol (i.e. $\left.\left(\mathrm{N}_{\text {INT }}+\mathrm{CDNC}\right) / \mathrm{N}_{\mathrm{PRE}}-\mathrm{CLOUD}=1.29\right)$. The $\mathrm{N}_{\text {INT }}$ derived by direct measurement is greater than that inferred by particle balance, which by definition gives $\left(\mathrm{N}_{\mathrm{INT}}+\right.$ $\mathrm{CDNC}) / \mathrm{N}_{\text {PRE}}-\mathrm{CLOUD}=1.0$. Allowance for a $19 \%$ contribu- tion from shatter reduces the imbalance to a factor of 1.20. This factor represents a combination of measurement error and methodological bias including but not limited to an activation threshold different than $100 \mathrm{~nm}$. The fraction of precloud aerosol not activated ( $\mathrm{N}_{\text {INT }} / \mathrm{N}_{\text {PRE-CLOUD }}$ ) has an average value of 0.48 based on measured values of $\mathrm{N}_{\text {INT }}$, which reduces to 0.39 after accounting for an average shatter fraction of $19 \%$.

\subsubsection{Interstitial aerosol - CDNC anti-correlation}

Interstitial aerosol were anti-correlated with CDNC in all 102 cloud transects. Similar observations have been made by others (e.g. Gultepe et al., 1996; Wang et al., 2009). As a representative example we consider a case study cloud observed on Flight 081028a, centered at $75.2^{\circ} \mathrm{W}$ (Fig. 2). Figure 13a shows a $1 \mathrm{~Hz}$ time series of CDNC and $\mathrm{N}_{\mathrm{INT}}$ measured with the CAS and inside-cabin PCASP, respectively. There are multiple spikes lasting no more than $1 \mathrm{~s}$ in which a decrease in CDNC is accompanied by an increase in $\mathrm{N}_{\text {INT }}$. There are also variations on time scales of tens of seconds or longer in which the relation between CDNC and $\mathrm{N}_{\mathrm{INT}}$ is less apparent. 
A plot of CDNC vs. NINT (Fig. 13b) shows an overall anti-correlation but with considerable scatter. The anticorrelation that is apparent in the high frequency spikes in Fig. 13a is partially obscured by changes in pre-cloud aerosol and/or cloud dynamics that are important over spatial scales of order $5 \mathrm{~km}$ and greater. In order to account for the nonuniformity of the cloud, we qualitatively separate low and high frequency components. A $400 \mathrm{~s}$ binomial filter, subjectively selected, has been applied, yielding low frequency components shown by red lines in Fig. 13a. High frequency components called anomalies to avoid confusion with $10 \mathrm{~Hz}$ data presented later on are defined as the difference between a $1 \mathrm{~Hz}$ signal and the corresponding low frequency filtered component. A graph of high frequency anomalies in Fig. 13c has reduced scatter.

Low frequency changes in aerosol and cloud droplets contribute to scatter in Fig. 13b. Cloud regions which have different aerosol inputs or different dynamics can have CDNC vs. aerosol plots that are shifted relative to each other. In Fig. 13d, the original $1 \mathrm{~s}$ data has been subject to a $10 \mathrm{~s}$ running box car average, which is a visual aid to picking out contiguous points. Lines are drawn between consecutive data points and color coded to correspond to the time sequence in Fig. 13a. One can pick out 4 or 5 strands that represent contiguous cloud portions up to $10 \mathrm{~km}$ in length that individually show an anti-correlation between CDNC and $\mathrm{N}_{\text {INT. Among }}$ the 102 clouds transects, this type of structure is common. At a still larger spatial scale approaching the length of the transect, CDNC and $\mathrm{N}_{\mathrm{INT}}$ are correlated (Fig. 13e). Depending on mesoscale structure, the low frequency changes in CDNC and $\mathrm{N}_{\text {INT }}$ can be correlated, anti-correlated, or scattered.

Higher frequency measurements are useful in interpreting the presence of interstitial aerosol. Increasing the time response of cloud droplet measurements to $10 \mathrm{~Hz}$ as in Fig. 14, shows that the cloud contains regions in which CDNC decreases to near zero accompanied by large decreases in LWC but relatively small changes in volume mean radius. It is expected that the interstitial aerosol shows similar high frequency structure but this is not observable with our sampling line.

A regression between the high frequency anomalies of CDNC and accumulation mode aerosols has a slope of -2.0 for the case study cloud in Fig. 13, approximately equal to the median slope of -2.1 found for the entire data set of 102 clouds. Several factors contribute to the slope being steeper than minus 1 , the value that would be obtained if removal of a single cloud droplet resulted in the appearance of an interstitial aerosol particle detected by the PCASP. First is the possibility of an overestimate in CDNC as suspected from the intercomparison data in Table 2. If actual CDNC are $80 \%$ of measured, correcting the $\mathrm{CDNC}$ changes the slope by a factor of 0.8 (i.e. from -2 to -1.6 ). Second, cloud droplets could be formed from aerosol particles smaller than the $110 \mathrm{~nm}$ lower limit of detection of the PCASP. Sub-cloud aerosol size distributions have a Hoppel minimum at $\sim 75 \mathrm{~nm}$, indicating
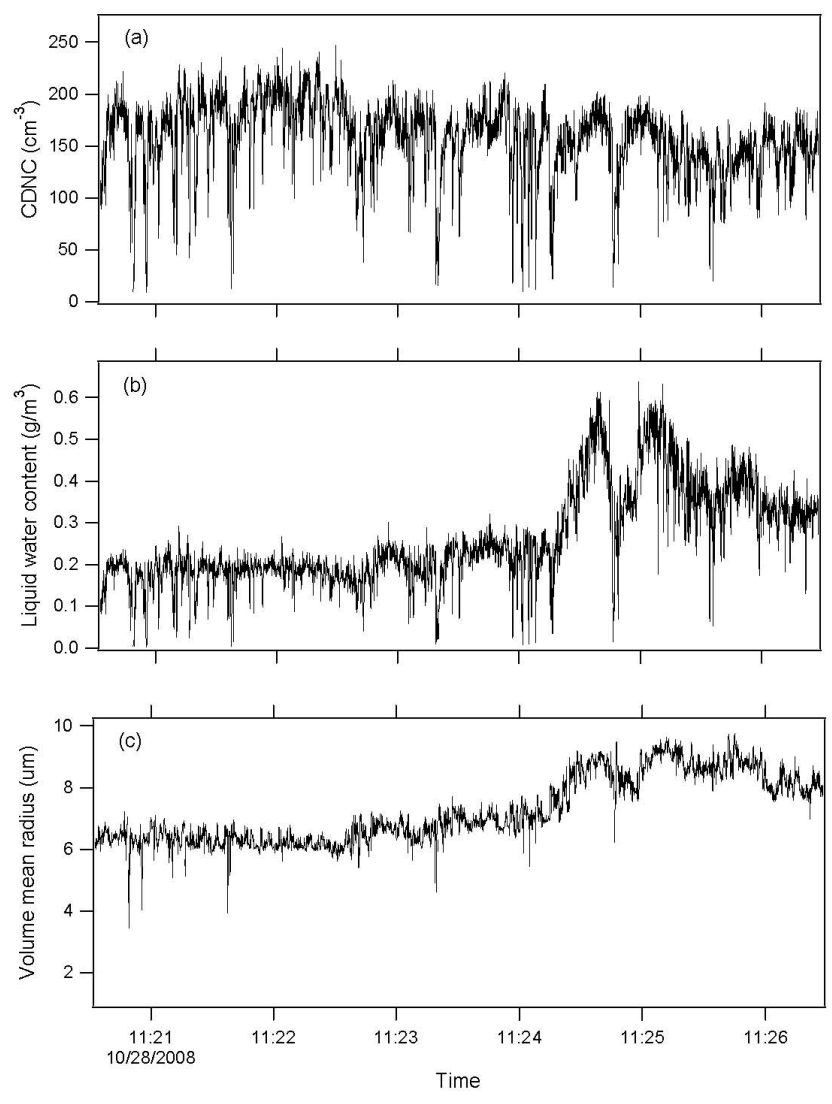

Fig. 14. (a) Cloud droplet number concentration, (b) liquid water content, and (c) cloud droplet volume mean radius for the same cloud transect and time period used in Fig. 13. Data collected at $10 \mathrm{~Hz}$ shows increased structure, in particular containing holes with near zero cloud droplet concentration and LWC. Distance covered is $35 \mathrm{~km}$, comparable to the size of mesoscale structures apparent on satellite photos. Note change in cloud properties near 11:24:30.

that sometime in the air mass history, particles of that size were activated (Cantrell et al., 1999). Third, is a degraded time response due to mixing in the inlet manifold leading to the inside-cabin PCASP. This effect has been simulated by constructing a PCASP signal which is the negative of CDNC, then subjecting it to 3 point binomial smoothing to simulate mixing. The resulting regression slope between the high frequency components of CDNC and the synthetic PCASP signal was -1.49 , instead of -1 before smoothing. Results depend on the degree of smoothing and our choice is meant to be only illustrative. Supporting evidence for the importance of time response comes from the PCASP mounted on the aircraft nose which yields a median slope of -1.35 .

The case study cloud shown in Figs. 13 and 14 is representative in many ways, but as a single cloud is not meant to illustrate features resulting from the natural range in adiabaticity, position relative to cloud top and bottom, aerosol concentration, LWC, drizzle, and mesoscale structure seen during VOCALS. 


\section{Discussion}

\subsection{First indirect effect}

Cloud reflectivity (albedo) is dependent on many processes, the relation between cloud droplets and aerosol (Fig. 10) being only one component. More important to reflectivity is cloud liquid water path or, given a fixed cloud depth, liquid water content (Schwartz and Slingo, 1996; Brenguier et al., 2000). Measurements during VOCALS along $20^{\circ} \mathrm{S}$ from $\sim 72$ to $86^{\circ} \mathrm{W}$ indicate that the westward decrease in aerosol concentration is accompanied by an increase in cloud depth and liquid water path (Allen et al., 2011; Bretherton et al., 2010) so that changes in reflectivity seen from satellites have to be apportioned between dynamical effects and aerosol perturbations, with the possibility that the two effects are coupled (Stevens and Feingold, 2009). The first indirect effect, which corresponds to the change in cloud reflectivity caused by an aerosol perturbation, can be masked by other aspects of cloud physics. An example of dynamical and aerosol effects operating in different directions is provided by our case study cloud. In that case interstitial aerosol decreases with westward distance in agreement with trends observed for below-cloud aerosol (Figs. 3 and 4a). By itself the decrease in aerosol is expected to lead to fewer but larger cloud droplets and a less reflective cloud towards the west. However, Fig. 14b and c, show an abrupt increase in cloud liquid water content and droplet size that presumably has a dynamic origin, positioned such that a decrease in cloud albedo caused by fewer aerosol particles is opposed by an increase in cloud albedo (dependent on cloud depth variations) caused by increased liquid water.

\subsection{Interstitial aerosol}

In an adiabatic cloud, a high activation fraction should follow from the combination of chemical composition, size distribution, and vertical velocity, $w$, observed during the VOCALS campaign. This is supported by results from an adiabatic parcel model (Robinson, 1984), initialized with the MBL average aerosol size distributions observed at 71-72 and 76-77 longitude, corresponding to relatively high and low concentrations, respectively. It was assumed that aerosol had the properties of $\left(\mathrm{NH}_{4}\right)_{2} \mathrm{SO}_{4}$, which in terms of hygroscopicity is a close approximation to the actual composition. Bretherton et al. (2010) report standard deviations of $w$ centered on $0.4 \mathrm{~m} \mathrm{~s}^{-1}$ for near shore cloud measurements from the $\mathrm{C} 130$. At a vertical velocity of $0.4 \mathrm{~m} \mathrm{~s}^{-1}$ the critical diameter for activation is calculated to be 110 and $85 \mathrm{~nm}$ for the high and low concentration aerosol environments, respectively.

Air parcel calculations should take into account the range in $w$ (i.e., the pdf as used by e.g. Snider and Brenguier, 2000 and Snider et al., 2003) which brings in values lower (and higher) than the median, opening the way for some large particles to remain unactivated. However as pointed out by
Guibert et al. (2003) particles respond to the supersaturation existing along their trajectories and a very low vertical velocity at cloud base may not be persistent. Also, no account is taken of entrainment.

A common feature of most cloud transects is that $\mathrm{N}_{\text {INT }}$ rarely approaches zero even in regions with high CDNC or high LWC, i.e., regions most likely to have a high updraft velocity and/or be close to adiabatic. At the highest aerosol concentrations this might be due to competition for liquid water during ascent. However, this phenomena also occurs at low aerosol concentration, as in the case illustrated in Fig. 13. Whereas rapid increases in $\mathrm{N}_{\text {INT }}$ that coincide with a decrease in CDNC (Fig. 13a-d) have a physical explanation, the "background" $\mathrm{N}_{\mathrm{INT}}$ does not have a clear interpretation and may be associated with droplet scatter and/or droplet evaporation. This "background" presumably contributes to the excess of in-cloud particles compared with pre-cloud air (Fig. 10).

Regarding the high frequency component of $\mathrm{N}_{\text {INT }}$, it has a plausible magnitude after due consideration is given to the inside-cabin PCASP response time. It also has a plausible mechanism as cloud top entrainment of dry air evaporates cloud droplets leaving behind interstitial aerosol particles. The anti-correlation could also be explained in terms of regions with weak updrafts. Depending on the horizontal dimensions of the entrained air or weak updraft, the time sequence of anti-correlated CDNC and $\mathrm{N}_{\mathrm{INT}}$ (Fig. 13a) will be more or less spiky as observed from a moving platform. We have shown $1 \mathrm{~Hz}$ and $10 \mathrm{~Hz}$ data but it is known that clouds are inhomogeneous on smaller scales (Gerber et al., 2005).

\section{Conclusions}

During the VOCALS-REx field campaign, the DOE G-1 covered a longitude range between Arica on the coast of Chile $\left(70.3^{\circ} \mathrm{W}\right)$ and $78^{\circ} \mathrm{W}$, an $800 \mathrm{~km}$ distance over which MODIS retrievals show a strong gradient in CDNC and effective radius. Aerosol number and volume concentration in the MBL decreased with off-shore distance with most of the decrease occurring between the coast and $75^{\circ} \mathrm{W}$. This pattern is consistent with the trajectory analysis of Allen et al. (2011) and Bretherton et al. (2010) that indicate a source region to the south along the Chilean coast, whose impact is felt most often east of $75^{\circ} \mathrm{W}$ and with decreasing frequency further west. MBL concentrations of $\mathrm{O}_{3}$ increase with distance from the coast while $\mathrm{CO}$ concentrations decrease indicating a nearby continental source for the latter.

Aerosol in the MBL is acidic sulfate with a $10-15 \%$ admixture of organics consistent with emissions dominated by $\mathrm{SO}_{2}$ point sources (Lee et al., 2011). MBL aerosol have an Aitken and accumulation mode with geometric mean diameters of $45-60 \mathrm{~nm}$ and $160-185 \mathrm{~nm}$, respectively, separated by a Hoppel minimum. In the FT, number size distributions are unimodal and broad, centered at $90 \mathrm{~nm}$. 
In each of three altitude ranges, collectively spanning the FT from 1200 to $3000 \mathrm{~m}$, dew point varied by more than $40{ }^{\circ} \mathrm{C}$, showing that within a narrow altitude span, air masses with very different histories were sampled. The requirement that an ascending air mass has a relative humidity less than $100 \%$, combined with a strong dependence of temperature on altitude implies that the lowest dew point air observed $\left(-40^{\circ} \mathrm{C}\right.$ ) originated above $8 \mathrm{~km}$ altitude (assuming a surface temperature of $15^{\circ} \mathrm{C}$ and a lapse rate of $6.5^{\circ} \mathrm{C} \mathrm{Km}^{-1}$, for purpose of illustration). Conversely, moist air implies a low altitude source.

Frequency distributions of $\mathrm{CO}, \mathrm{O}_{3}$, aerosol number, and aerosol volume are provided as functions of altitude and dew point. Using dew point in place of altitude has the advantage of separating air masses according to history and highlights the different behavior of soluble and insoluble pollutants (Kleinman and Daum, 1991). Dew point more clearly picks up trends in $\mathrm{O}_{3}$ because $\mathrm{O}_{3}$ has a source in the dry upper atmosphere and a MBL sink. There is a pronounced decrease in aerosol volume with dew point as low dew point air masses have been subject to cloud processes that have removed all but a few percent of their total water. Removed along with water are soluble substances such as accumulation mode particles that are $\mathrm{CCN}$. The decrease with dew point of aerosol number concentration is less extreme because of the dominance of smaller less easily activated particles in the FT. The FT population of aerosol, however, does contain some accumulation mode size particles $\left(D_{p}>100 \mathrm{~nm}\right)$ which will subside into the MBL, much the same as $\mathrm{O}_{3}$, thereby providing a source of CCN to replace that lost by drizzle (Clarke et al., 1996, 1997). Relative solubility may play a role in the 5 fold increase in the organic aerosol to sulfate ratio with decreasing dew point. It is also possible that the high ratio at low $T_{d}$ reflects emission rates in areas not impacted by $\mathrm{SO}_{2}$ sources. Even with an elevated organic to sulfate ratio in dry air, the organic aerosol to $\mathrm{CO}$ ratio is an order of magnitude lower than observed in day old plumes in the boundary layer in other field studies.

Comparison was made between (a) pre-cloud aerosol and cloud droplets and (b) between pre-cloud air and the sum of interstitial aerosol and cloud droplets. According to comparisons " $a$ " and " $b$ " the fraction of pre-cloud aerosol that is interstitial is $27 \%$ and $48 \%$, respectively. In comparison " $b$ " there is a $29 \%$ over-prediction of total particles in-cloud, assuming a $100 \mathrm{~nm}$ critical diameter for activation. Droplet shatter and evaporation of cloud droplets during in-cloud aerosol sampling are discussed as possible artifacts. Pursuant to methodological assumptions, droplet shatter contributes close to $20 \%$ of interstitial aerosol larger than $100 \mathrm{~nm}$, and a rapidly decreasing fraction at larger diameter. Adiabatic parcel model calculations based on measured aerosol composition, concentration, size distribution, and a $0.4 \mathrm{~m} \mathrm{~s}^{-1}$ vertical velocity yield a critical diameter for activation between 85 and $110 \mathrm{~nm}$, for clean and polluted conditions. While this support the use of $100 \mathrm{~nm}$ as a lower bound to aerosol diam- eter in comparisons "a" and "b", it yields fewer interstitial aerosol than observed.

One hundred and two constant altitude cloud transects were identified and used to examine relations between CDNC and the number concentration of interstitial aerosol (NINT) as measured by a heated PCASP inside the aircraft cabin. In each transect CDNC and $\mathrm{N}_{\text {INT }}$ are anti-correlated, suggesting that a decrease in cloud droplets by e.g. evaporation leads to the appearance of interstitial aerosol. One cloud sampled over a $35 \mathrm{~km}$ transect was selected for a case study. Within this cloud there were 4 or 5 regions with distinctly different relations between CDNC and $\mathrm{N}_{\mathrm{INT}}$ contributing to scatter over the $35 \mathrm{~km}$ cloud. Much of the scatter could be removed by applying a high pass filter and examining anomalies determined as the total signal less the low frequency variation. The in-cloud aerosol concentration contains high frequency components that are a possible source of information on particle activation and/or evaporation sitting on top of a low frequency background, the later partly due to scatter and partly of unknown origin, that we tentatively associate with an over prediction of interstitial aerosol.

Acknowledgements. We thank chief pilot Bob Hannigan and the flight crew from PNNL for a job well done. Thanks to Robert McGraw of BNL for droplet evaporation calculations. We gratefully acknowledge the Atmospheric Science Program within the Office of Biological and Environmental Research of DOE for supporting field and analysis activities and for providing the G-1 aircraft. Use of a c-ToF-AMS provided by EMSL is appreciated. The VOCALS Regional Experiment owes its success to many people. We would like to single out Robert Wood (Univ. of Washington), Christopher Bretherton (Univ. of Washington), and C.'Roberto Mechoso (UCLA) for their organizational skills and scientific leadership. S. S. Yum is partially supported by the Korean Meteorological Administration Research and Development Program under Grant RACS 2010-5001. This research was performed under sponsorship of the US DOE under contracts DE-AC02-98CH10886.

Edited by: C. Twohy

\section{References}

Allen, G., Coe, H., Clarke, A., Bretherton, C., Wood, R., Abel, S. J., Barrett, P., Brown, P., George, R., Freitag, S., McNaughton, C., Howell, S., Shank, L., Kapustin, V., Brekhovskikh, V., Kleinman, L., Lee, Y.-N., Springston, S., Toniazzo, T., Krejci, R., Fochessato, J., Shaw, G., Krecl, P., Brooks, B., McMeeking, G., Bower, K. N., Williams, P. I., Crosier, J., Crawford, I., Connolly, P., Allan, J. D., Covert, D., Bandy, A. R., Russell, L. M., Trembath, J., Bart, M., McQuaid, J. B., Wang, J., and Chand, D.: Southeast Pacific atmospheric composition and variability sampled along $20^{\circ} \mathrm{S}$ during VOCALS-REx, Atmos. Chem. Phys., 11, 5237-5262, doi:10.5194/acp-11-5237-2011, 2011.

Ayers, G. P., Penkett, S. A., Gillett, R. W., Bandy, B., Galbally, I. E., Meyer, C. P., Elsworth, C. M., Bentley, S. T., and Forgan, B. 
W.: Evidence for photochemical control of ozone concentrations in unpolluted marine air, Nature, 360, 446-449, 1992.

Brechtel, F. J.: Description and assessment of a new aerosol inlet for the DOE G-1 research aircraft, final technical report of work performed by BMI under contract \#0000058843 to Brookhaven National Laboratory, August 2003.

Brenguier, J.-L., Pawlowska, H., Schüller, L., Preusker, R., Fisher, J., and Fouquart, Y.: Radiative properties of boundary layer clouds: Droplet effective radius versus number concentration, J. Atmos. Sci., 57, 803-821, 2000.

Bretherton, C. S., Wood, R., George, R. C., Leon, D., Allen, G., and Zheng, X.: Southeast Pacific stratocumulus clouds, precipitation and boundary layer structure sampled along $20^{\circ} \mathrm{S}$ during VOCALS-Rex, Atmos. Chem. Phys., 10, 10639-10654, doi:10.5194/acp-10-10639-2010, 2010.

Cantrell, W., Shaw, G., and Benner, R.: Cloud properties inferred from bimodal aerosol number distribution, J. Geophys. Res., 104, 27615-27624, 1999.

Chand, D., Hegg, D. A., Wood, R., Shaw, G. E., Wallace, D., and Covert, D. S.: Source attribution of climatically important aerosol properties measured at Paposo (Chile) during VOCALS, Atmos. Chem. Phys., 10, 10789-10801, doi:10.5194/acp-1010789-2010, 2010.

Clarke, A. D., Li, Z., and Litchy, M.: Aerosol dynamics in the equatorial Pacific Marine boundary layer: Microphysics, diurnal cycles and entrainment, Geophys. Res. Lett., 23, 773-736, 1996.

Clarke, A. D., Uehara, T., and Porter, J. N.: Atmospheric nuclei and related aerosol fields over the Atlantic: Clean subsiding air and continental pollution during ASTEX, J. Geophys. Res., 102, 25281-25292, 1997.

Clegg, S. L., Brimblecombe, P., and Wexler, A. S.: A thermodynamic model of the system $\mathrm{H}^{+}-\mathrm{NH}_{4}^{+}-\mathrm{SO}_{4}^{2-}-\mathrm{NO}_{3}^{-}-\mathrm{H}_{2} \mathrm{O}$ at tropospheric temperatures, J. Phys. Chem. A, 102, 2137-2154, 1998.

Clegg, S. L. and Wexler, A. S.: Densities and apparent molar volumes of atmospherically important electrolyte solutions. 2 . The system $\mathrm{H}^{+}-\mathrm{HSO}_{4}^{-}-\mathrm{SO}_{4}^{2-}-\mathrm{H}_{2} \mathrm{O}$ from $0-3 \mathrm{~mol} \mathrm{~kg}^{-1}$ as a function of temperature and $\mathrm{H}^{+}-\mathrm{NH}_{4}^{+}-\mathrm{HSO}_{4}^{-}-\mathrm{SO}_{4}^{2-}-\mathrm{H}_{2} \mathrm{O}$ from 0 $6 \mathrm{~mol} \mathrm{~kg}^{-1}$ at $25^{\circ} \mathrm{C}$ using a Pitzer ion interaction model, and $\mathrm{NH}_{4} \mathrm{HSO}_{4}-\mathrm{H}_{2} \mathrm{O}$ and $\left(\mathrm{NH}_{4}\right)_{3} \mathrm{H}\left(\mathrm{SO}_{4}\right)_{2}-\mathrm{H}_{2} \mathrm{O}$ over the entire concentration range. J. Phys. Chem. A 115, 3461-3474, 2011.

Collins, D. R., Flagan, R. C., and Seinfeld, J. H., Improved inversion of scanning DMA data, Aerosol Sci. Technol., 36, 1-9, 2002.

Draxler, R. R. and Rolph, G. D.: HYSPLIT (HYbrid SingleParticle Lagrangian Integrated Trajectory) Model access via NOAA ARL READY Website available at: http://ready.arl.noaa. gov/HYSPLIT.php, last access: January 2011, NOAA Air Resources Laboratory, Silver Spring, MD, USA, 2010.

Faloona, I., Lenschow, D. H., Campos, T., Stevens, B., van Zanten, M., Blomquist, B., Thornton, D., Bandy, A., and Gerber, H.: Observations of entrainment in Eastern Pacific marine stratocumulus using three conserved scalers, J. Atmos. Sci., 62, 3268-3285, 2005.

Fountoukis, C., Nenes, A., Meskhidze, N., Bahreini, R., Conant, W. C., Jonsson, H., Murphy, S., Sorooshian, A., Varutbangkul, V., Brechtel, F., Flagan, R. C., and Seinfeld, J. H.: Aerosol-cloud drop concentration closure for clouds sampled during the Intercontinental Consortium for Atmospheric Research on Transport and Transformation 2004 campaign, J. Geophys. Res., 112,
D10S30, doi:10.1029/2006JD007272, 2007.

Gerber, H., Arends, B. G., and Ackerman, A. S.: A new microphysics sensor for aircraft use, Atmos, Res., 31, 235-252, 1994.

Gerber, H., Frick, G., Malinowski, S. P., Brenguier, J.-L., and Burnet, F.: Holes and entrainment in stratocumulus, J. Atmos. Sci., 62, 443-459, 2005.

Gillani, N. V., Schwartz, S. E., Leaitch, W. R., Strapp, J. W., and Isaac, G. A.: Field observations in continental stratiform clouds: Partitioning of cloud particles between droplets and unactivated interstitial aerosols, J. Geophys. Res., 100, 18687-18706, 1995.

Guibert, S., Snider, J. R., and Brenguier, J.-L.: Aerosol activation in marine stratocumulus clouds: 1. Measurement validation for a closure study, J. Geophys. Res., 108, 8628, doi:10.1029/2002JD002678, 2003.

Gultepe, I., Isaac, G. A., Leaitch, W. R., and Banic, C. M.: Parameterizations of marine stratus microphysics based on in situ observations: Implications for GCMs, J. Climate., 9, 345-357, 1996.

Hallar, A. G., Strawa, A. W., Schmid, B., Andrews, E., Ogren, J., Sheridan, P., Ferrare, R., Covert, D., Elleman, R., Jonsson, H., Bokarius, K., and Luu, A.: Atmospheric Radiation Measurements Aerosol Intensive Operating Period: Comparison of aerosol scattering during coordinated flights, J. Geophys. Res., 111, D05S09, doi:10.1029/2005JD006250, 2006.

Hallberg, A., Noone, K. J., Ogren, J. A., Svenningsson, I. B., Flossmann, A., Wiedensohler, A., Hansson, H.-C., Heintzenberg, J., Anderson, T. L., Arends, B. G., and Maser, R., Phase partitioning of aerosol particles in clouds at Kleiner Feldberg, J. Atmos. Chem., 19, 107-127, 1994.

Henning, S., Weingartner, E., Schmidt, S., Wendisch, M., Gäggeler, H. W., and Baltensperger, U., Size-dependent aerosol activation at the high-alpine site Jungfraujoch (3580 $\mathrm{m}$ asl), Tellus, 54B, 82-95, 2002.

Hoppel, W. A., Frick, G. M., and Larson, R. E.: Effects of nonprecipitating clouds on the aerosol size distribution in the marine boundary layer, Geophys. Res. Lett., 13, 125-128, 1986.

Hudson, J. G. and Frisbie, P. R.: Cloud condensation nuclei near marine stratus, J. Geophys. Res., 96, 20795-20808, 1991.

Kleinman, L. I. and Daum, P. H.: Vertical distribution of aerosol particles, water vapor, and insoluble trace gases in convectively mixed air, J. Geophys. Res., 96, 991-1005, 1991.

Kleinman, L. I., Daum, P. H., Lee, Y.-N., Senum, G. I., Springston, S. R.,Wang, J., Berkowitz, C., Hubbe, J., Zaveri, R. A., Brechtel, F. J., Jayne, J., Onasch, T. B., and Worsnop, D.: Aircraft observations of aerosol composition and ageing in New England and Mid-Atlantic States during the summer 2002 New England Air Quality Study field campaign, J. Geophys. Res., 112, D09310, doi:10.1029/2006JD007786, 2007.

Kleinman, L. I., Springston, S. R., Daum, P. H., Lee, Y.-N., Nunnermacker, L. J., Senum, G. I., Wang, J., Weinstein-Lloyd, J., Alexander, M. L., Hubbe, J., Ortega, J., Canagaratna, M. R., and Jayne, J.: The time evolution of aerosol composition over the Mexico City plateau, Atmos. Chem. Phys., 8, 1559-1575, doi:10.5194/acp-8-1559-2008, 2008.

Kleinman, L. I. et al.: Interactive comment on "Aerosol concentration and size distribution below, in, and above cloud from the DOE G-1 during VOCALS-REx”, Atmos. Chem. Phys. Discuss., 11, C6380-C6384, doi:10.5194/acpd-11-C6380-2011, 2011.

Kley, D., Crutzen, P. J., Smit, H. G. J., Vömel, H., Oltmans, S. 
J., Grassl, H., and Ramamathan, V.: Observations of near-zero ozone concentrations over the convective Pacific: Effects on air chemistry, Science, 274, 230-233, 2006.

Lance, S., Brock, C. A., Rogers, D., and Gordon, J. A.: Water droplet calibration of the Cloud Droplet Probe (CDP) and inflight performance in liquid, ice, and mixed-phase clouds during ARPAC, Atmos. Meas. Tech., 3, 1683-1706, doi:10.5194/amt3-1683-2010, 2010.

Lance, S.: Interactive comment on "Aerosol concentration and size distribution measured below, in, and above cloud from the DOE G-1 during VOCALS-REx" by L. I. Kleinman et al., Atmos. Chem. Phys. Discuss., 11, C5622-C5623, doi:10.5194/acpd-11C5622-2011, 2011.

Leaitch, W. R., Strapp, J., and Isaac, G. A.: Cloud droplet nucleation and cloud scavenging of aerosol sulphate in polluted atmospheres, Tellus, 38B, 328-344, 1986.

Leaitch, W. R., Banic, C. M., Isaac, G. A., Couture, M. D., Liu, P. S. K., Gultepe, I., Li, S.-M., Kleinman, L. I., Daum, P. H., and MacPherson, J. I.: Physical and chemical observations in marine stratus during the 1993 North Atlantic Regional Experiment: Factors controlling cloud droplet number concentrations, J. Geophys. Res., 101, 29123-29135, 1996.

Lee, Y.-N., Springston, S., Jayne, J., Wang, J., Senum, G., Hubbe, J., Alexander, L., Brioude, J., Spak, S., Mena-Carrasco, M., Kleinman, L., and Daum, P.: Aerosol composition, chemistry, and source characterization during the 2008 VOCALS Experiment, Atmos. Chem. Phys. Discuss., in preparation, 2011.

Martinsson, B. G., Frank, G., Cederfelt, S.-I., Swietlicki, E., Berg, O. H., Zhou, J., Bower, K. N., Bradbury, C., Birmili, W., Stratmann, F., Wendisch, M., Wiedensohler, A., and Yuskiewicz, B. A.: Droplet nucleation and growth in orographic clouds in relation to the aerosol population, Atmos. Res., 50, 289-315, 1999.

McGraw, R., and Liu, Y.: Brownian drift-diffusion model for evolution of droplet size distributions in turbulent clouds, Geophys. Res. Lett., 33, L03802, doi:10.1029/2005GL023545, 2006.

Mertes, S., Lehmann, K., Nowak, A., Massling, A., and Wiedensohler, A.: Link between aerosol hygroscopic growth and droplet activation observed for hill-capped clouds at connected flow conditions during FEBUKO, Atmos. Environ., 39, 4247-4256, 2005.

Parrish, D. D., Trainer, M., Holloway, J. S., Yee, J. E., Warshawsky, M. S., Fehsenfeld, F. C., Forbes, G. L., and Mody, J. L.: Relationship between ozone and carbon monoxide at surface sites in the North Atlantic region, J. Geophys. Res., 103, 13357-13376, 1998.

Rahn, D. A., and Garreaud, R.: Marine boundary layer over the subtropical southeast Pacific during VOCALS-REx - Part 1: Mean structure and diurnal cycle, Atmos. Chem. Phys., 10, 4491-4506, doi:10.5194/acp-10-4491-2010, 2010.

Ramanathan, V., Crutzen, P. J., Kiehl, J. T., and Rosenfeld, D.: Aerosols, climate, and the hydrological cycle, Science, 294, 2119-2124, 2001.

Robinson, N. F.: The efficient numerical calculation of condensational cloud droplet growth, J. Atmos. Sci., 41, 698-700, 1984.

Schwartz, S. E. and Slingo, A.: Enhanced shortwave cloud radiative forcing due to anthropogenic aerosols, in Clouds, Chemistry and Climate - Proceedings of NATO Advanced Research Workshop, Ringberg, Germany, 21-25 March 1994, edited by: Crutzen, P. and Ramanathan, V., Springer, Heidelberg, Germany, 191-236, 1996.
Snider, J. R. and Brenguier, J.-L.: Cloud condensation nuclei and cloud droplet measurements during ACE-2, Tellus, 52B, 828842, 2000.

Snider, J. R. and Petters, M. D., Optical particle counter measurement of marine aerosol hygroscopic growth, Atmos. Chem. Phys., 8, 1949-1962, doi:10.5194/acp-8-1949-2008, 2008.

Snider, J. R., Guibert, S., Brenguier, J.-L., and Putard, J.-P.: Aerosol activation in marine stratocumulus clouds: 2. Köhler and parcel theory closure studies, J. Geophys. Res., 108, 8629, doi:10.1029/2002JD002692, 2003.

Stevens, B. and Feingold, G.: Untangling aerosol effects on clouds and precipitation in a buffered system, Nature, 461, 607-613, 2009.

Strapp, J. W., Leaitch, W. R., and Liu, P. S. K.: Hydrated and dried aerosol-size distribution measurements fro the Particle Measuring Systems FSSP-300 Probe and the deiced PCASP-100X Probe, J. Atmos. Oceanic Technol., 9, 548-555, 1992.

Springston, S. R., Kleinman, L. I., Nunnermacker, L. J., Brechtel, F., Lee, Y.-N., and Wang, J.: Chemical evolution of an isolated power plant plume during the TexAQs 2000 study, Atmos. Environ., 39, 3431-3443, 2005.

Twohy, C. H., Petters, M. D., Snider, J. R., Stevens, B., Tahnk, W., Wetzel, M., Russell, L., and Burnet, F.: Evaluation of the aerosol indirect effect in marine stratocumulus clouds: Droplet number, size, liquid water path, and radiative impact, J. Geophys. Res., 110, D08203, doi:10.1029/2004JD005116, 2005.

Wang, J., Daum, P. H., Yum, S. S., Liu, Y., Senum, G. I., Lu, M.-L., Seinfeld, J. H., and Jonsson, H.: Observations of marine stratocumulus microphysics and implications for processes controlling droplet spectra: Results from the Marine Stratus/Stratocumulus Experiment, J. Geophys. Res., 114, D18210, doi:10.1029/2008JD011035, 2009.

Weber, R. J., Clarke, A. D., Litchy, M., Li, J., Kok, G., Schillawski, R. D., and McMurry, P. H.: Spurious aerosol measurements when sampling from aircraft in the vicinity of clouds, J. Geophys. Res., 103, 28337-28346, 1998.

Wood, R., Bretherton, C., Huebert, B., Mechoso, C. R., and Weller, R., VOCALS-SouthEast Pacific Regional Experiment (REx) Scientific Program Overview, available online at: http://www.eol.ucar.edu/projects/vocals/documentation/ vocals_overview.pdf last access: January 2011, June 2007.

Wood, R., Mechoso, C. R., Bretherton, C. S., Weller, R. A., Huebert, B., Straneo, F., Albrecht, B. A., Coe, H., Allen, G., Vaughan, G., Daum, P., Fairall, C., Chand, D., Gallardo Klenner, L., Garreaud, R., Grados, C., Covert, D. S., Bates, T. S., Krejci, R., Russell, L. M., de Szoeke, S., Brewer, A., Yuter, S. E., Springston, S. R., Chaigneau, A., Toniazzo, T., Minnis, P., Palikonda, R., Abel, S. J., Brown, W. O. J., Williams, S., Fochesatto, J., Brioude, J., and Bower, K. N.: The VAMOS Ocean-Cloud-Atmosphere-Land Study Regional Experiment (VOCALS-REx): goals, platforms, and field operations, Atmos. Chem. Phys., 11, 627-654, doi:10.5194/acp-11-6272011, 2011.

Yang, Q., W. I. Gustafson Jr., Fast, J. D., Wang, H., Easter, R. C., Morrison, H., Lee, Y.-N., Chapman, E. G., Spak, S. N., and Mena-Carrasco, M. A.: Assessing regional scale predictions of aerosols, marine stratocumulus, and their interactions during VOCALS-REx using WRF-Chem, Atmos. Chem. Phys., 11, 11951-11975, doi:10.5194/acp-11-11951-2011, 2011. 